\title{
Carbon Dots as a Sustainable New Platform for Organic Light Emitting Diode
}

\author{
Paola Lagonegro, Umberto Giovanella *(D) and Mariacecilia Pasini *(D) \\ Istituto di Scienze e Tecnologie Chimiche "Giulio Natta" (SCITEC), Consiglio Nazionale delle Ricerche (CNR), \\ via A. Corti 12, 20133 Milano, Italy; paola.lagonegro@scitec.cnr.it \\ * Correspondence: umberto.giovanella@scitec.cnr.it (U.G.); mariacecilia.pasini@scitec.cnr.it (M.P.)
}

check for

updates

Citation: Lagonegro, P.; Giovanella, U.; Pasini, M. Carbon Dots as a Sustainable New Platform for Organic Light Emitting Diode. Coatings 2021, 11, 5. https://dx.doi. org/10.3390/ coatings11010005

Received: 17 November 2020 Accepted: 15 December 2020 Published: 23 December 2020

Publisher's Note: MDPI stays neutral with regard to jurisdictional claims in published maps and institutional affiliations.

Copyright: (c) 2020 by the authors. Licensee MDPI, Basel, Switzerland. This article is an open access article distributed under the terms and conditions of the Creative Commons Attribution (CC BY) license (https: / / creativecommons.org/ licenses/by/4.0/).
Abstract: Over the past 10 years, carbon dots (CDs) synthesized from renewable raw materials have received considerable attention in several fields for their unique photoluminescent properties. Moreover, the synthesis of CDs fully responds to the principles of circular chemistry and the concept of safe-by-design. This review will focus on the different strategies for incorporation of CDs in organic light-emitting devices (OLEDs) and on the study of the impact of CDs properties on OLED performance. The main current research outcomes and highlights are summarized to guide users towards full exploitation of these materials in optoelectronic applications.

Keywords: carbon dots; organic light-emitting diode; photoluminescence

\section{Introduction}

The growing demand for electronic devices for an ever-increasing number of applications means that green and sustainable electronics are no longer just a dream but a pressing need [1].

In this context, the electronics and optoelectronics based on organic semiconductors showed, in the last few years, significant growth in many areas dominated by traditional electronics [2]. The foremost advantage of organic materials is that they are cheap, lightweight, easy to be processed, and flexible [3]. However, the synthetic techniques currently used for production of organic semiconductors [4] suffer from toxicity and environmental problems that can seriously prevent their large-scale production. In this regard, application of the principles of green chemistry for development of synthetic sustainable methods for the synthesis of semiconductors is essential to support the development of organic electronics, thus moving towards increasingly sustainable electronic devices [5].

In fact, the use of organic materials to build electronic devices [6] holds the promise that future electronic manufacturing methods will rely on safer and more abundant raw materials [7]. The vision is for resource-efficient synthetic methodologies, whereby both devices themselves and manufacturing of those devices use less materials and more safe materials.

The first pillar on which the new sustainable industrial revolution is based on is inevitably the development of new materials that are possibly safe and sustainable by design [8].

Among the emerging classes of materials able to meet these needs, carbon dots (CDs) are attracting considerable interest. They are part of the nanocarbon family, and differently from the best known carbon nanotube [9], they include quasi-spherical nanoparticles with sizes around $10 \mathrm{~nm}$. Since their first discovery in 2006, CDs [10,11] have gained everincreasing attention due to their fascinating properties like distinctive optical behavior, tunable emission, different functional groups, good biocompatibility, chemical and photostability, low toxicity, and low-cost production. More importantly, CDs properties can be changed by controlling their size, shape, and heteroatom doping and by modifying the surfaces, thanks to the quantum confinement effect (QCE) [12] (Figure 1). They are 
considered promising green alternatives to fluorescent dyes [13-15] and generally to toxic metallic colloidal semiconductor nanocrystals and have been proposed for optoelectronic applications in general [12,16-19] (Figure 1), such as sensing, bioimaging, fingerprint detection, gene delivery, solar cells, or printing inks.

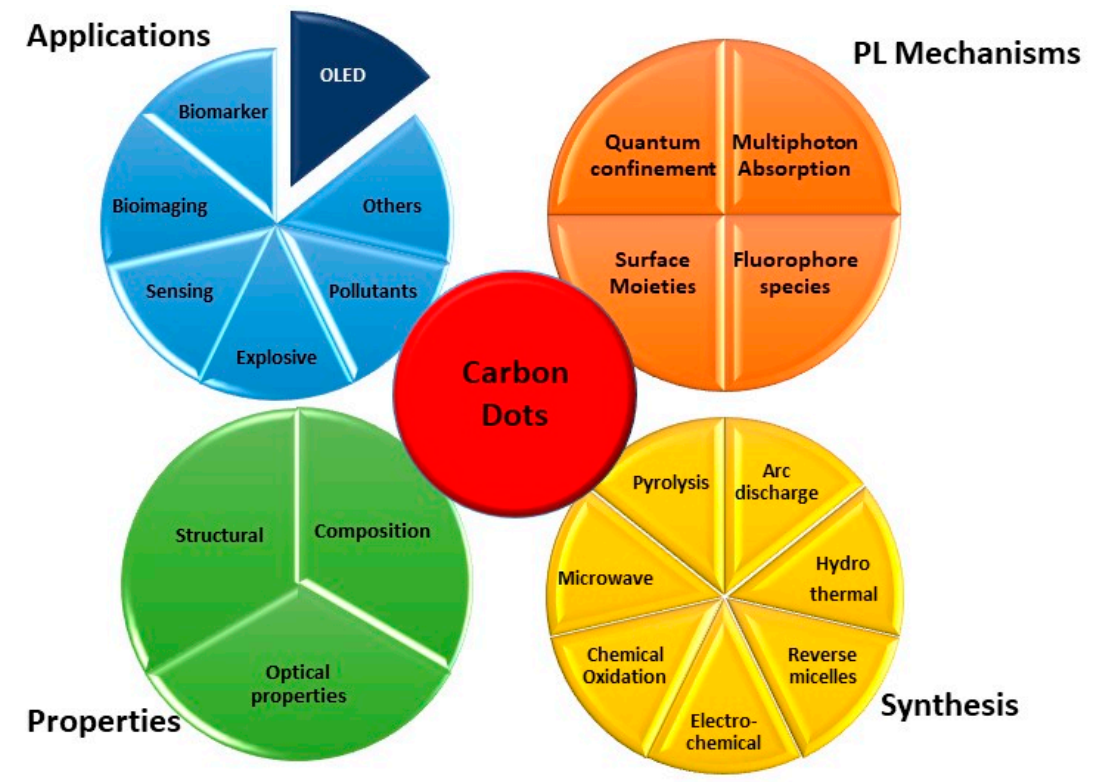

Figure 1. Carbon dots general overview.

In general, $\mathrm{CD}$ preparation methods can be grouped into two main approaches: topdown and bottom-up. The first strategy [20-27] involves the use of techniques such as arc discharge, laser ablation, chemical oxidation in strong acid, and electrochemical synthesis to break down carbon sources such as graphite, carbon nanotubes, and nanodiamonds to form fluorescent CDs. In contrast, in the bottom-up approach [28-34], CDs are synthesized from organic molecules by applying hydrothermal solvothermal methods, ultrasonic or microwave treatments, or simple thermal combustion.

Although CDs have been synthesized from different starting materials with a great variety of techniques, there is a huge effort to develop sustainable synthetic paths which adhere to the principles of green chemistry. It has been demonstrated that CDs can be obtained from any carbon-based materials. This, in particular, guarantees that most by-products of the food supply chain can be reused to produce CDs. Agriculture products contain a myriad of natural molecules that can make up a diverse source of surface functional groups in $\mathrm{CD}$ formation.

A relevant feature for $\mathrm{CD}$ sustainability has to do with synthetic methodologies for their fabrication. CDs can be produced hydrothermally, that is, by heating the starting materials in water under atmosphere or elevated pressure [28-31,34,35]. Consequently, the cost of production is low, and the operation is easy, relatively safe, and free from organic solvents (Figure 2). Furthermore, shorter processing time and lower energy consumption for CD manufacture can be obtained when microwaves are used as the heating source [36,37].

Toxicity studies of the CDs were performed with both plants and animals (mice), revealing good biocompatibility [38-40], and opened the way not only to their bio-application but also to biodegradable electronics $[19,40]$. 


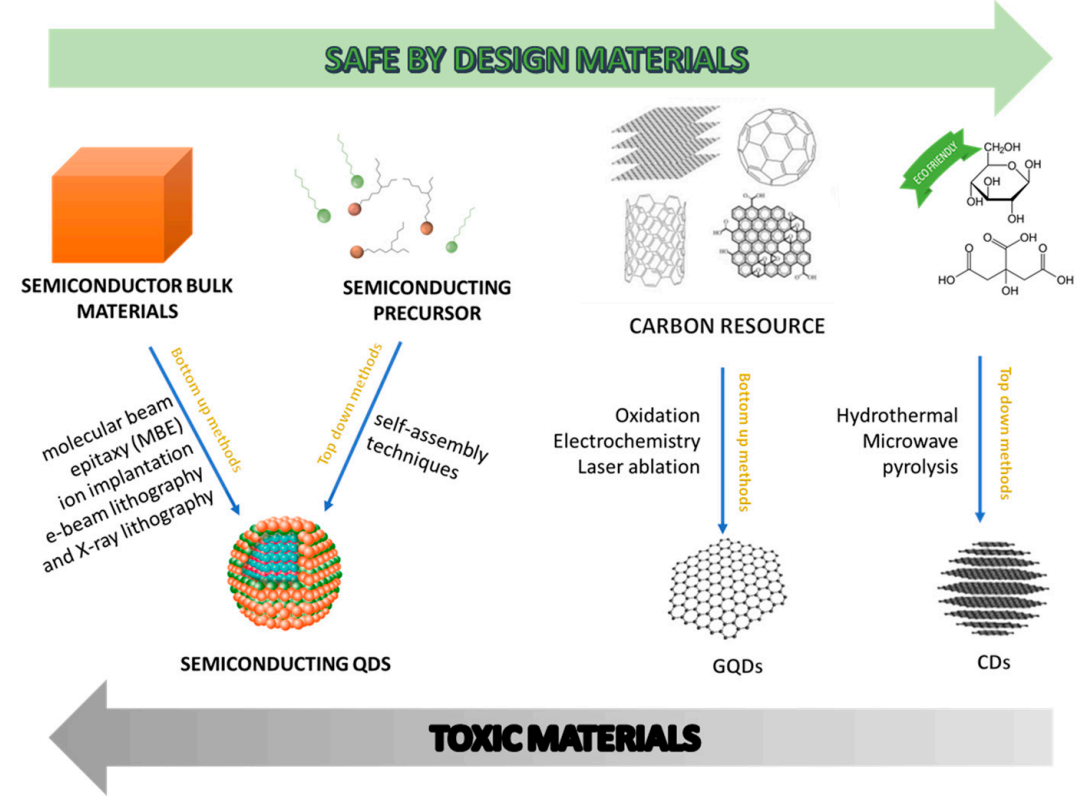

Figure 2. Schematic representation of carbon dots' main characteristics: adapted with permission from [14], copyright 2019 American chemical society, and adapted with permission from [41], copyright 2017 Elsevier.

With this perspective, in the present review, we will discuss CDs obtained with a bottom-up approach as it is the one that best adheres to the principles of green chemistry. They can be obtained from renewable sources or waste such as citric acid or agricultural waste [37]. The synthetic methodologies are simple and inexpensive, and they do not require the use of metal catalysts or chlorinated solvents. We will focalize on CDs as a sustainable new platform for organic light-emitting device (OLED) technology $[42,43]$ without deepening the methods of synthesis on which relevant works have already been written [28-37,44]. In fact, among the various interesting applications of organic electronics, OLEDs are certainly those that have already carved out a slice of the market [42], and for this reason, the development of sustainable active materials and green technologies can already help the economy make a green turn.

In the next Section 2, we will make a brief introduction on the type and optical properties of these luminescent carbon materials. Section 3 will cover the different applications in electroluminescence devices as active layers or as charge regulating layers. In the last section, we will give some perspectives for the use of CDs including potential applications and possible development in particular as a safe-by-design material. We hope that this review will provide new insights to develop new knowledge on CDs, from the point of view of both sustainable synthesis and multiple applications, so that their potential in the optoelectronics area can be consolidated.

\section{Definition of Carbon Dots and Optical Properties}

Since their fortuitous discovery in 2004 by $\mathrm{Xu}$ et al. [10] and subsequently by Sun et al. in 2006 [11], CDs attracted a great deal of attention. Generally, CDs are 0-dimension nanocarbons with a typical size of less than $10 \mathrm{~nm}$, although approximately 60-nm-size CDs have also been reported. CDs are quasispherical nanoparticles consisting of amorphous and crystalline parts, mainly composed of carbon with a fringe spacing of $0.34 \mathrm{~nm}$, which corresponds to the (002) interlayer spacing of graphite [12-14]. CDs are often confused, or associated, with graphene quantum dots (GQDs) [15], which are always part of the family of carbon-based nanomaterials but have different characteristics and origins. In fact, GQDs are nanofragments of graphene exhibiting a graphene structure inside the dots with a typical fringe spacing of $0.24 \mathrm{~nm}$ associated with the (100) in-plane lattice spacing of graphene. They have only one or a few layers of graphene with variable thickness between 
2 and $10 \mathrm{~nm}$ and with usually $100 \mathrm{~nm}$ in lateral dimension, and they are generally produced by converting graphene or graphene oxide via top-down approaches [14].

Over the last 15 years, CDs have been synthesized with different approaches (i.e., topdown and bottom-up). However, only recently, sustainable precursors and methodologies have been deeply investigated for their production $[45,46]$. These approaches look for sustainable materials which are low-cost, scalable, industrially and economically attractive, and based on renewable and highly abundant resources. This means that CD synthesis can meet the requirements of circular chemistry. Interestingly, CDs after synthesis can be further functionalized with various surface groups. In particular, oxygen-based functional groups, such as carboxyl and hydroxyl, give excellent solubility in water and are suitable for surface passivation and derivatization with various organic materials. Surface functionalization modifies both the physical properties of CDs such as their solubility in aqueous and nonaqueous solvents and their optical properties. For example, after surface passivation, the fluorescence properties of CDs can be improved [47,48]. In addition, the large conjugated structure endows CDs with some important characteristics, like good photostability, high surface area, and robust surface grafting [49]. Their electronic structures can be tuned by their size, shape, surface functional groups, and heteroatom doping, as theoretically investigated and experimentally confirmed by several groups [50-54]. The tunability of optoelectronic properties by modifying synthetic parameters and precursor strictly resembled the conjugated polymer features [55].

As mentioned above, the $\mathrm{CD}$ emission properties are their most amazing characteristics [41] and significant advances have been made in the last years, reaching photoluminescence (PL) quantum yields (PLQYs) up to $80 \%$ in CDs produced from citric acid as a renewable precursor or bright and stable PLQYs of $26 \%$ converting toxic cigarette butts $[28,54]$.

Mostly, CDs are blue emitters, but emissions from ultraviolet to near-infrared [55-58] as well as white light emission [59] were reported. In general, their PL spectra are symmetrical and broad, with large Stokes shifts (mainly due to the CD size distribution), and usually have an excitation-dependent behavior, with the emission peak varying with the excitation wavelength $[22,58]$.

The emission mechanism of CDs is a longstanding debate, and several hypotheses have been proposed [41] (see Figure 3) such as (i) size-dependent emission, (ii) surface state-derived luminescence, and (iii) embedded molecular luminophore [60]. Regardless of the type of mechanism, it has been shown that CD emissions could be regulated by controlling their size (mainly referring to $\mathrm{sp}_{2}$ carbon domains), their surface passivation and/or functionalization, and their doping due to the presence of heteroatom [61-63].

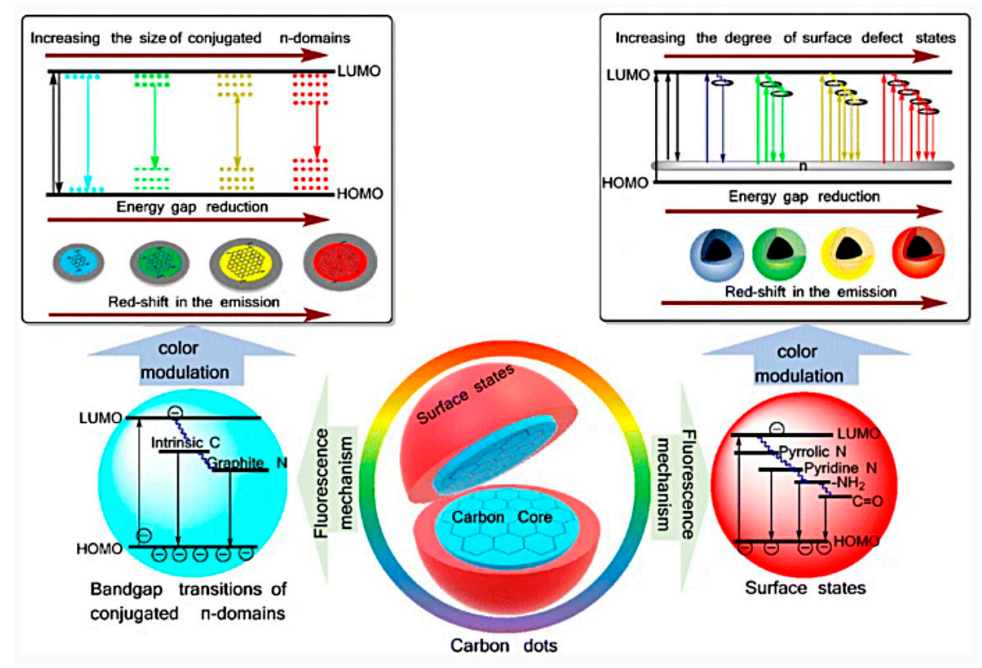

Figure 3. Different hypotheses for carbon dot (CD) emission mechanism: reprinted with permission from [64], copyright 2019 Springer Nature. 
The first hypothesis proposed is based on the size of CDs [60]. Yuan and coworkers synthetized multicolor-emitting CDs with different dimensions from citric acid (CA) and diaminonaphthalene (DAN) by controlling the process parameters. CDs showed average sizes of about 1.95, 2.41,3.78, 4.90, and $6.68 \mathrm{~nm}$ (Figure 4A), with corresponding tunable absorption (Figure 4B) blue $(430 \mathrm{~nm})$, green $(513 \mathrm{~nm})$, yellow $(535 \mathrm{~nm})$, orange $(565 \mathrm{~nm})$, and red $(565 \mathrm{~nm})$ emissions, respectively (Figure $4 \mathrm{C})$. In accordance with the results, they deduced that, by increasing the size of $\mathrm{CDs}$ and consequently the conjugated $\pi$-domain, the bandgap decreases (Figure 4D,E) [65].
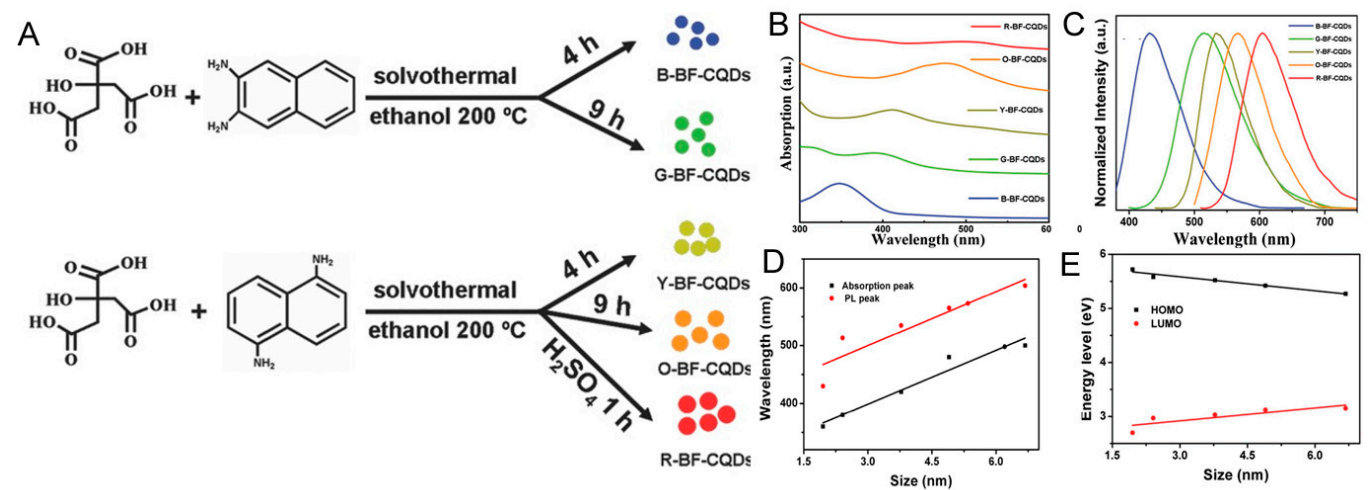

Figure 4. Preparation of bright multicolor bandgap fluorescent (BF) CDs by solvothermal treatment of citric acid (CA) and diaminonaphthalene (DAN) (A) from blue to red (B-E): (A) reprinted with permission from [14], copyright 2019 American Chemical Society, and (B-E) reprinted with permission from [65], copyright 2016 WILEY-VCH Verlag GmbH \& Co. KGaA, Weinheim.

A second hypothesis is related to the surface states of CDs. Ding et al. [66] synthetized tunable photoluminescent CDs by one-pot hydrothermal synthesis (Figure 5A). Noteworthy, these CDs had comparable particle size and carbon core but variable degree of oxidation of the surface state. Therefore, a gradual reduction in their band gaps and a red shift in their emission peaks from 440 to $625 \mathrm{~nm}$ (Figure 5B,C) was observed by increasing the incorporation of oxygen species into their surface structures (Figure 5D) [66].

Also, Miao et al. [67] hypothesized a similar mechanism. They modulated the CD emission from 430 to $630 \mathrm{~nm}$ by controlling the degree of graphitization and the number of surface $-\mathrm{COOH}$ groups by changing the molar ratios of $\mathrm{CA}$ to urea at different temperatures (Figure 6). The increasing number of $-\mathrm{COOH}$ groups on the surface increases the electronic delocalization, and the emission wavelength is consequently red-shifted [64].

Another relevant hypothesis to explain CD emission is molecular luminophorederived emission or molecular state emission. Small molecules or oligomeric luminophores could be produced during CD synthesis, and these luminophores could be attached to the surface of $\mathrm{CD}$ backbones, allowing $\mathrm{CDs}$ to have bright emission properties [68]. Song et al. [69] studied the chemical structure and PL mechanism of CDs from CA and ethylenediamine (EDA). They proved the presence of a type of bright blue fluorophore and that $\mathrm{CD}$ emission was a result of small molecules, polymer clusters, and carbon cores. Indeed, the fluorophore may be attached to the carbon core, that may strongly affect the PL properties of the CDs. 

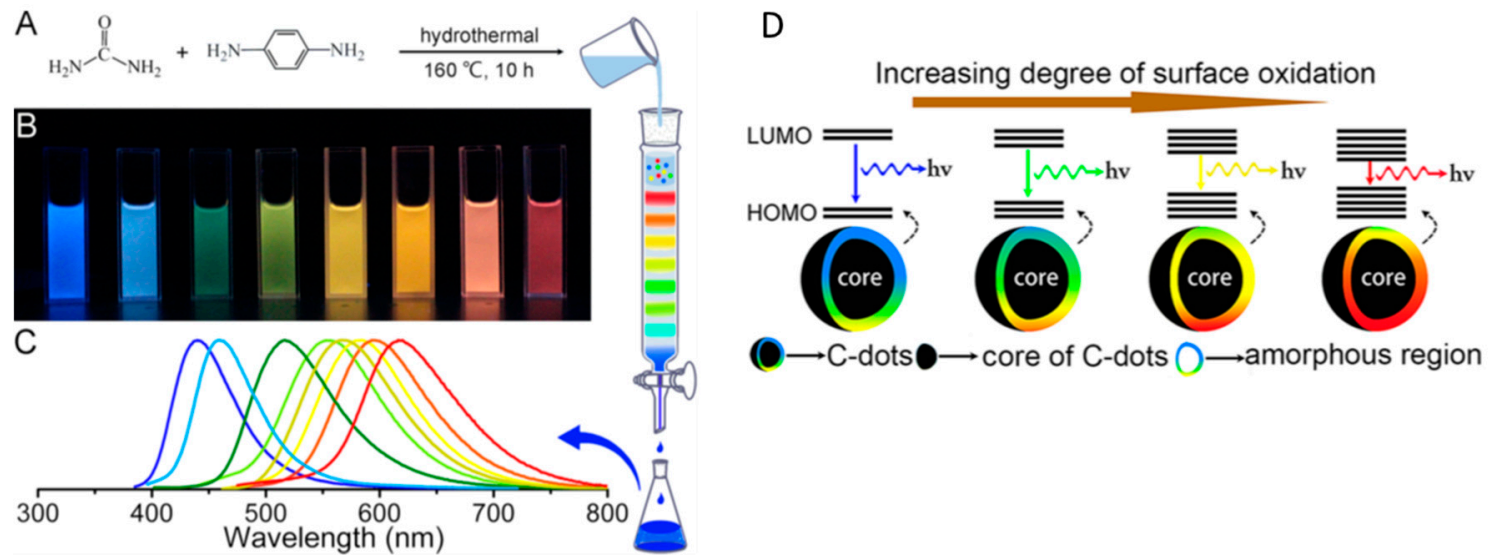

Figure 5. (A) One-pot synthesis and purification route for CDs with distinct photoluminescence (PL) characteristics, (B) eight CD samples under $365 \mathrm{~nm}$ UV light, (C) corresponding PL emission spectra, and (D) model for the tunable PL of CDs with different degrees of oxidation: reprinted with permission from [70], copyright 2016 American chemical society.

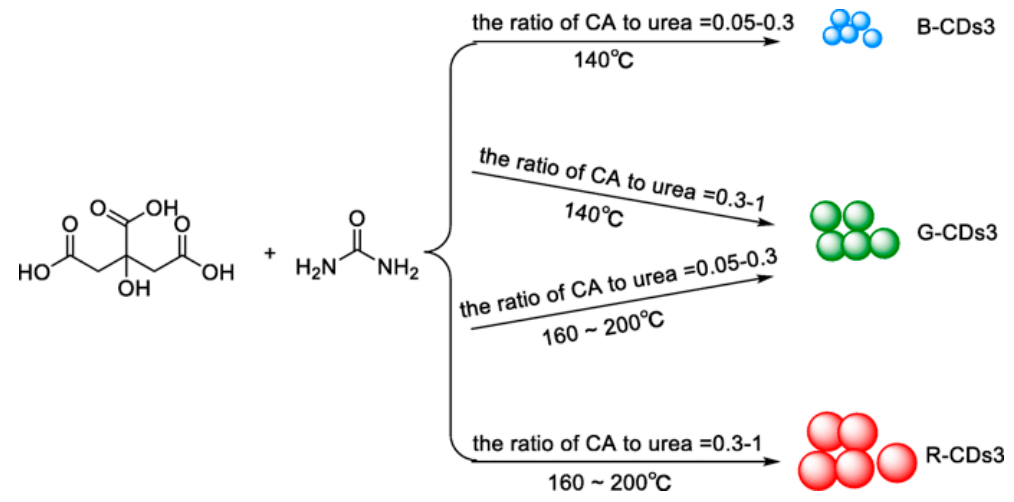

Figure 6. Multicolor-emitting CDs (called as CDs3) by using different molar ratios of CA to urea at different temperatures: the emission of CDs3 can be adjusted from 430 to $630 \mathrm{~nm}$. The photoluminescence quantum yields (PLQYs) of the three CDs3 in blue, green, and red were $52.6 \%, 35.1 \%$, and $12.9 \%$, respectively. Reprinted with permission from [64], copyright (2019) Springer-Verlag.

\section{OLED-Based Carbon Dots}

CDs with amazing properties such as optical characteristics and carbon's intrinsic merits of high stability, low-cost, and environment-friendliness find natural and practical applications as components in OLED technology.

In the last decade, the interest in OLED based on CDs (hereafter CD-OLEDs) has been growth, and an increasing number of research groups have started to investigate in this field.

We want to provide a recent overview on CD-OLEDs, illustrating the dual employment of CDs as emitter, both as neat layer or as a guest in host-guest systems, and as a charge regulating interlayer (Table 1 and Figure 7). Particular attention will be devoted to the strategies used to prevent aggregation-induced quenching in the solid-state and to tune the emission color. It is also important to underline, although beyond the scope of this collection, that many groups used CDs also as a remote emitter, endowing blue commercial LEDs with a color converting filter based on CDs embedded in poly (methyl-methacrylate) (PMMA) or other matrices. The blue LED emission was tuned from blue to red by altering the film thickness of the filter or the doping concentration of CDs [68-72]. 
Table 1. Summary of organic light-emitting devices (OLEDs) incorporating a CD layer.

\begin{tabular}{|c|c|c|c|c|c|}
\hline Starting Materials & $\begin{array}{l}\text { Dimension } \\
(\mathrm{nm}) / \text { Shape }\end{array}$ & $\mathrm{EL}_{\text {PEAK }}(\mathrm{nm})$ & $\mathrm{L}_{\text {MAX }}\left(\mathrm{cd} / \mathrm{m}^{2}\right)$ & $\eta_{c}(\mathrm{Cd} / \mathrm{A})$ & Ref. \\
\hline CDs as neat emitter & - & - & - & - & - \\
\hline \multirow{5}{*}{$\begin{array}{l}\text { Citric acid with } \\
\text { 2,3-diaminonaphthalene }\end{array}$} & $1.95 \mathrm{~nm}$ & 455 & 136 & 0.084 & \multirow{5}{*}{ [65] } \\
\hline & $2.41 \mathrm{~nm}$ & 536 & 93 & 0.045 & \\
\hline & $3.78 \mathrm{~nm}$ & 555 & 60 & 0.02 & \\
\hline & $4.9 \mathrm{~nm}$ & 585 & 65 & 0.027 & \\
\hline & $6.68 \mathrm{~nm}$ & 628 & 12 & 0.0028 & \\
\hline $\begin{array}{l}\text { ethylenediamine and phthalic } \\
\text { acid }\end{array}$ & $5.53 \mathrm{~nm}$ & 455 & 4.97 & - & [66] \\
\hline $\begin{array}{l}\text { citric acid + octadecene + } \\
\text { 1-hexadecylamine }\end{array}$ & Spherical $5 \mathrm{~nm}$ & $550-670$ & 35 & 0.022 & [73] \\
\hline 1-octadecene 1-hexadecylamine & $6 \pm 1.9 \mathrm{~nm}$ & 460 & 21 & 0.06 & [74] \\
\hline $\begin{array}{l}\text { 1-hexadecylamine and anhydrous } \\
\text { citric acid }\end{array}$ & \multirow{3}{*}{$3.3 \mathrm{~nm}$} & 426 & 24 & \multirow{3}{*}{0.018} & \multirow{3}{*}[75]{} \\
\hline $\begin{array}{l}\text { 1-hexadecylamine and anhydrous } \\
\text { citric acid }\end{array}$ & & $426,452,588$ & 61 & & \\
\hline $\begin{array}{l}\text { 1-hexadecylamine and anhydrous } \\
\text { citric acid }+\mathrm{ZnO} \text { nps }\end{array}$ & & $426,452,588$ & 90 & & \\
\hline $\begin{array}{l}\text { anhydrous citric acid and } \\
\text { hexadecylamine }\end{array}$ & $\begin{array}{l}\text { Spherical } 2.0-2.5 \mathrm{~nm} \\
\text { lattice spacing } 0.22\end{array}$ & 554 & 5.7 & & [76] \\
\hline CDs as guest emitter & - & - & - & - & - \\
\hline $\begin{array}{l}\text { citric acid and } \\
\text { diaminonaphthalene. }\end{array}$ & $\begin{array}{l}\text { quasi-spherical } 2.4 \\
\text { lattice spacing } 0.21 \mathrm{~nm}\end{array}$ & 450 & 5240 & 2.6 & [77] \\
\hline \multirow{4}{*}{ Phloroglucinol } & $\begin{array}{l}\text { triangular } \\
1.9 \mathrm{~nm}\end{array}$ & 476 & 1882 & 1.22 & \multirow{4}{*}{ [78] } \\
\hline & $2.4 \mathrm{~nm}$ & 510 & 4762 & 5.11 & \\
\hline & $3 \mathrm{~nm}$ & 540 & 2784 & 2.31 & \\
\hline & $3.9 \mathrm{~nm}$ & 602 & 2344 & 1.73 & \\
\hline $\begin{array}{c}\text { Citric acid with } \\
\text { 2,3-diaminonaphthalene }\end{array}$ & $2.41 \mathrm{~nm}$ & 536 & 2050 & 1.1 & [65] \\
\hline \multirow{2}{*}{ human hair } & \multirow{2}{*}{$\begin{array}{l}\text { 2D array of CDs } 2-6 \\
\mathrm{~nm}\end{array}$} & \multirow{2}{*}{498} & 350 & 0.22 & \multirow{2}{*}{ [79] } \\
\hline & & & 700 & 0.2 & \\
\hline $\begin{array}{c}\text { N,N-dimethyl-, N,N-diethyl-, and } \\
\text { N,N-dipropyl-p- } \\
\text { phenylenediamine }\end{array}$ & $\begin{array}{c}\text { quasi-spherical } 2.2 \pm \\
0.31 .2 .3 \pm 0.28 .2 .3 \pm \\
0.26 \mathrm{~nm} \text { lattice spacing } \\
0.21 \mathrm{~nm}\end{array}$ & $\begin{array}{l}605 / 434 \\
612 / 435 \\
616 / 435\end{array}$ & $5248-5909$ & $\begin{array}{l}3.65 \\
3.85\end{array}$ & [80] \\
\hline $\begin{array}{l}\text { anhydrous citric acid and } \\
\text { hexadecylamine }\end{array}$ & $\begin{array}{l}\text { spherical_2.0-2.5 nm } \\
\text { lattice spacing } 0.22\end{array}$ & $558-550$ & $339.5-455.2$ & - & [73] \\
\hline $\begin{array}{l}\text { anhydrous citric acid and } \\
\text { hexadecylamine }\end{array}$ & - & 474 & 569.8 & - & [81] \\
\hline CDs as interlayer & - & - & - & - & - \\
\hline ethylenediamine and citric acid & - & 532 & 30730 & 93.8 & [82] \\
\hline banana leaves & $\begin{array}{l}\text { 4-6 nm } \\
\text { (quasi-spherical) }\end{array}$ & 486 & - & - & [83] \\
\hline Ethanolamine & - & 622 & 3500 & 0.63 & [84] \\
\hline
\end{tabular}




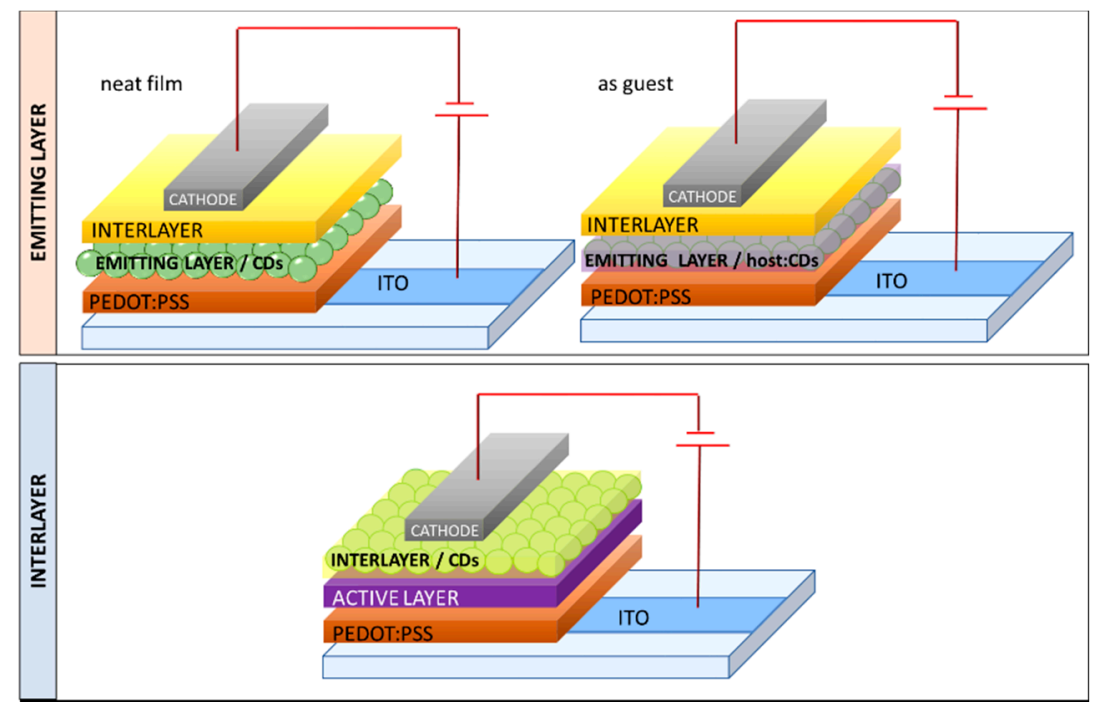

Figure 7. Scheme of the possible device architectures that incorporate $\mathrm{CD}$ as an emitter or as an interlayer.

\subsection{CDs as Emitter}

In 2011, Wang et al. [73] demonstrated the first white OLED (WOLED) originating from a single CD component film. CDs, obtained by thermal carbonization of CA in hot octadecene with 1-hexadecylamine (HDA) as the passivation agent (Figure 8a), with a PLQY as high as $60 \%$ were incorporated as an emitting layer in WOLEDs with a direct architecture (Figure 8b).

(b) Direct architecture

(a)

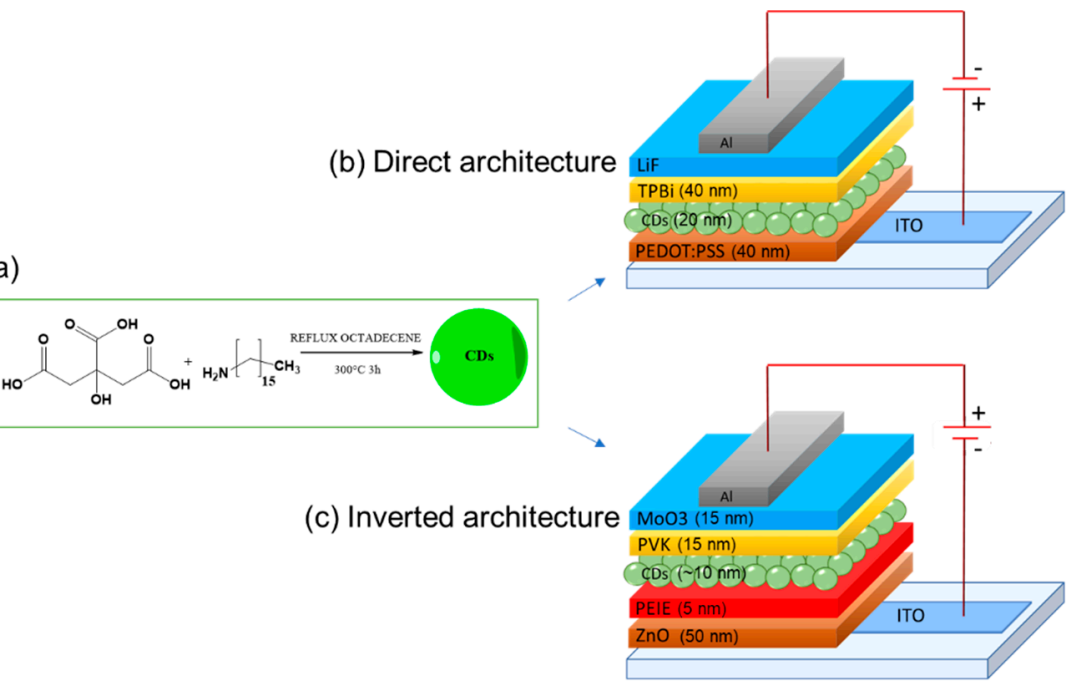

Figure 8. Schematic representation of (a) CD synthesis and typical devices architectures: (b) direct [74] and (c) inverted [73] in which CDs are incorporated as emitters.

Electrically driven WOLED-featured electroluminescence (EL) peaked at $550 \mathrm{~nm}$, with current density $(J)$ of $160 \mathrm{~mA} / \mathrm{cm}^{2}$, a maximum luminance $\left(L_{\text {MAX }}\right.$ ) output of $35 \mathrm{~cd} / \mathrm{m}^{2}$ (Figure $9 a, b)$, and a current efficiency $\left(\eta_{c}\right)$ of $0.022 \mathrm{~cd} / \mathrm{A}$. As shown in Figure $9 \mathrm{c}$, the maximum external quantum efficiency (EQE), defined as the ratio between the number of emitted photons and the number of electrons injected into the device, was $0.083 \%$ at a J of $5 \mathrm{~mA} / \mathrm{cm}^{2}$. 


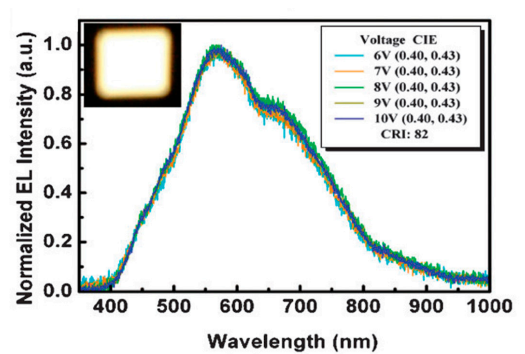

(a)

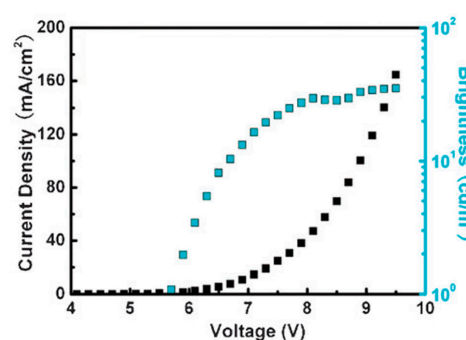

(b)

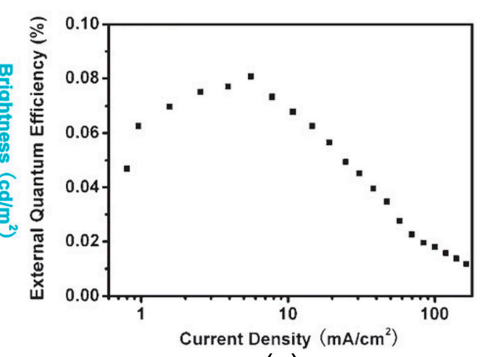

(c)

Figure 9. (a) Normalized electroluminescence (EL) spectra of direct architecture LEDs at applied bias voltages: the inset is a photograph of a white emission of our device $\left(16 \mathrm{~mm}^{2}\right)$ operating at $9 \mathrm{~V}$. (b) $J-L-V$ characteristics of white OLEDs (WOLEDs). (c) The dependence of external quantum efficiency (EQE) on J. Reproduced with permission from [73], copyright 2011 The Royal Society of Chemistry.

Wang et al. reported that white light emission was associated with energy transfer among various emitting centers in the CDs, corresponding to different energy transitions.

Paulo-Mirasol et al. [74], in 2019, by using CDs synthesized according to Wang conditions [73], demonstrated that the white light was not due to the charge transfer between the CDs but was the result of different recombination processes within the CDs. Indeed, they proposed two radiative PL mechanisms in the CDs, involving different energies: one originating from the core and a second process that is faster and originates from the surface of CDs. The variation of the current injection controls the activation of the two radiative processes that happen inside the CDs. The combined emission from different energy states results in white light emission at an adequate current injection rate. Differently from Wang and colleagues, Paulo-Mirasol et al. manufactured OLEDs with an inverted architecture ITO/ZnO/PEIE/CDs/PVK/ $\mathrm{MoO}_{3} / \mathrm{Au}$ (Figure 8c). They modulated the thickness of CDs and polyvinylcarbazole (PVK, well-known and used as a hole transporting layer or HTL) to optimize the performance of devices obtaining WOLEDs with $L_{\mathrm{MAX}}$ of $24 \mathrm{~cd} / \mathrm{m}^{2}$ and $\eta_{\mathrm{c}} 0.06 \mathrm{~cd} / \mathrm{A}$ (Figure 10) comparable to Wang's achievements $\left(L_{\mathrm{MAX}} 35 \mathrm{~cd} / \mathrm{m}^{2}\right.$ and $\eta_{\mathrm{c}}$ of $0.022 \mathrm{~cd} / \mathrm{A})$.
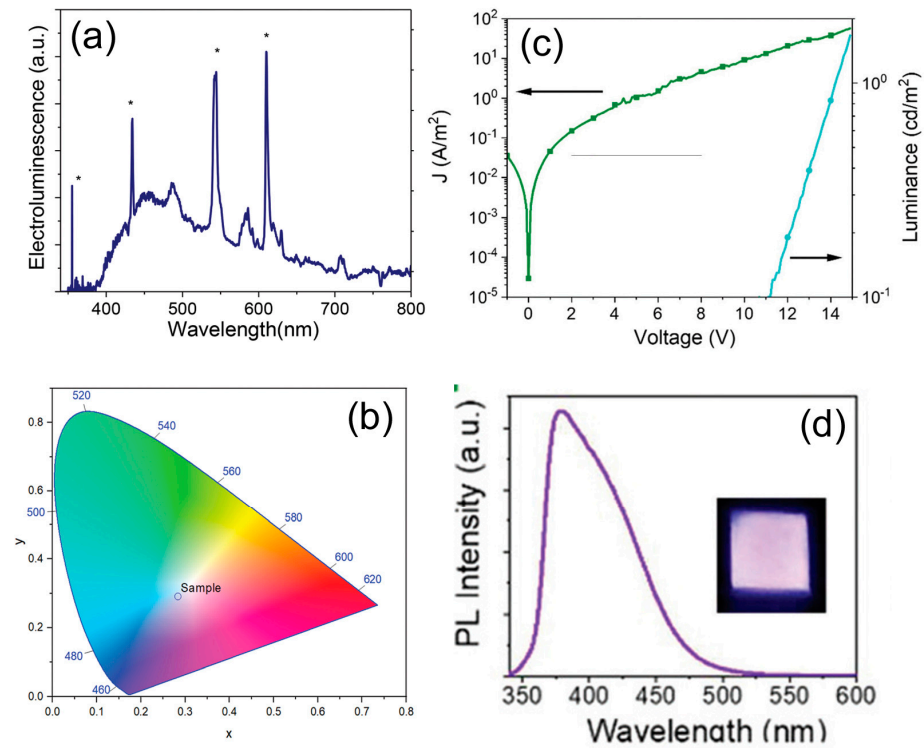

Figure 10. (a) The EL spectrum of CD-LED at $8 \mathrm{~V}$ (top); (b) CIE (Commission Internationale de l'Eclairage) color coordinates of LEDs with CDs as the single emitter, (c) J-L versus applied voltage of the LED made without CDs; (d) digital picture of the device using polyvinylcarbazole (PVK) as the emissive layer at $12 \mathrm{~V}$ and the photoluminescent emission spectra of the device after excitation at $340 \mathrm{~nm}$ : reproduced with permission from Reference [74], copyright 2019 The Royal Society of Chemistry. 
Ding and colleagues [66] proposed short-chain passivated CDs; in fact, the use of short chains allows for closer CDs, which probably facilitates the injection of carriers into CDs. Their CDs were synthesized via a one-step hydrothermal approach using phthalic acid and ethylenediamine. The resulting CD aqueous solution featured a PLQY of $29.3 \%$ and good film-forming ability. CD-OLEDs were fabricated by a solution processing method, and the devices exhibited a stable blue EL peak at $410 \mathrm{~nm}$ at 6-9 V. Despite improvement of the carrier transfer ability of CDs achieved by short-chain modification, the lower PLQY compared with that of long-chain passivated CDs and the not optimal device architecture (see the energy barrier at the anode interface in Figure 11a) were the most probable explanation for the lower performance observed in the devices (Figure 11b-d).
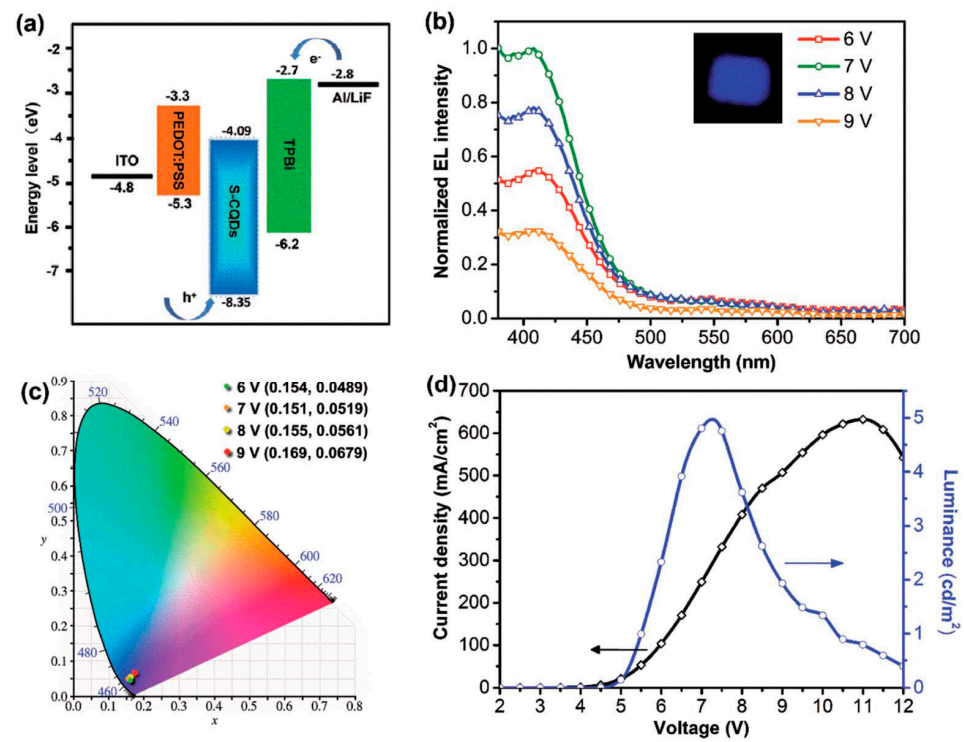

Figure 11. (a) The schematic energy level diagram of the CD-LEDs, (b) emission spectra at different working voltages (the inset is a photograph of CD-LEDs at 7 V), (c) the CIE 1931 chromaticity coordinates of CD-LEDs at different working voltages, and (d) $J-L-V$ characteristics of CD-LEDs: Reproduced with permission from [66], copyright 2017 The Royal Society of Chemistry.

Zhang at al. in 2013 [75] observed for the first time, a multi-colored (bright blue, cyan, magenta, and white) EL from CDs of the same size $(3.3 \mathrm{~nm})$. Such a switchable EL behavior had not been previously observed in single nanomaterial emitting layer OLEDs. This all-solution processed device consisted of a CD emissive layer sandwiched between an organic HTL and an organic or inorganic ETL (electron transporting layer, EIL) with typical architecture ITO/PEDOT:PSS/PolyTPD/CDs/TPBI (where poly-TPD was poly-(N,N'bis(4-butylphenyl)-N,N'-bis(phenyl) benzidine and TPBI 1,3,5-tris(N-phenylbenzimidazol2-yl) benzene)) or $\mathrm{ZnO} / \mathrm{LiF} / \mathrm{Al}$ (Figure 12A). The devices structure was adjusted to control $\mathrm{J}$ and, therefore, the EL spectra. By increasing LiF thickness from 1 at $5 \mathrm{~nm}$ or by replacing $\mathrm{LiF}$ and $\mathrm{TPBi}$ with $\mathrm{ZnO}$, the emitted color changed with the applied voltage from blue, cyan, and magenta and to white from the same carbon dots (Figure 12B-D).

The $L_{\mathrm{MAX}}$ obtained was $24 \mathrm{~cd} / \mathrm{m}^{2}$ for the blue-emitting OLED at low current injection. The $L_{\mathrm{MAX}}$ observed in devices incorporating $\mathrm{ZnO}$ nanoparticles was higher $\left(90 \mathrm{~cd} / \mathrm{m}^{2}\right)$ thanks to the higher electron mobility of $\mathrm{ZnO}$ with respect to organic ETLs.

To solve the problem of aggregation quenching of CDs, a host-guest approach $[85,86]$ has been proposed since 2017, with CDs as guest component and, usually, the PVK as a host matrix. 


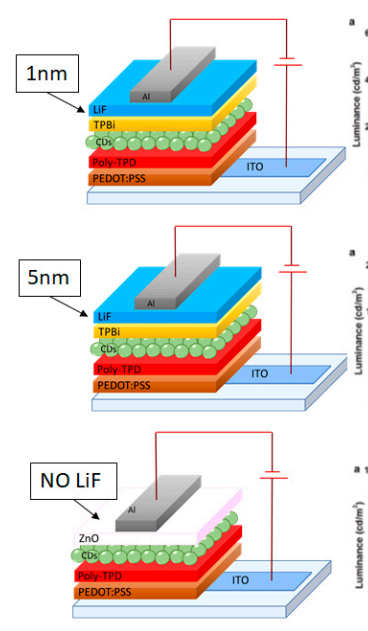

A
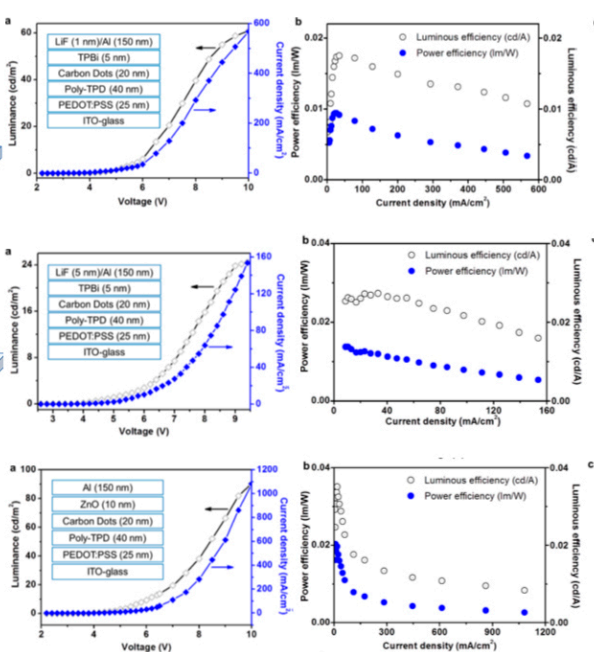

B
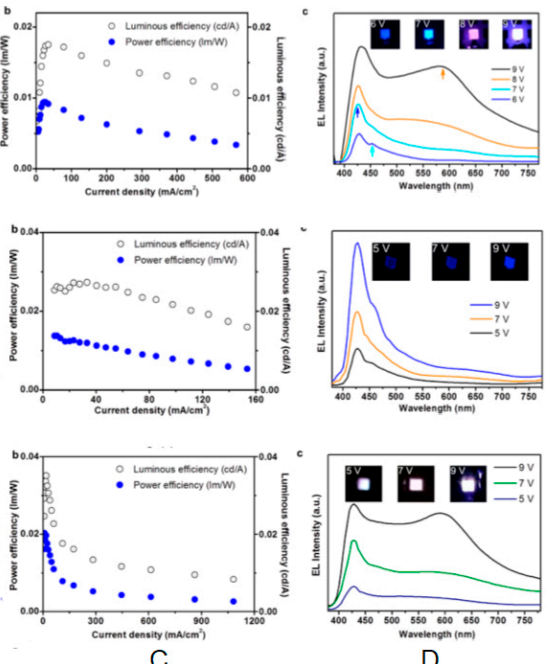

Figure 12. (A) Schematic representation of the CD-LED architectures together with (B) J and L versus $\mathrm{V},(\mathrm{C}) \eta_{\mathrm{c}}$ and power efficiencies vs. J, and (D) EL spectra and images of the operating CD-LEDs at different applied voltage: Reproduced with permission from [73], copyright 2013 American Chemical Society.

Yuan et al. [65] compared the performance of a neat CD film to those of CDs dispersed in PVK. They used bright multicolor blue-to-red fluorescent CDs (called MCBF-CDs) with PLQY up to 75\%, synthesized through a facile solvothermal method. Their CDs were $\mathrm{N}$-doped, highly surface passivated with a high degree of crystallinity. CDs were firstly employed as an active layer for monochromatic OLEDs with a basic architecture ITO/PEDOT:PSS/CDs/TPBI/Ca/Al (Figure 13a). Monochrome OLEDs featured blue (B), green $(\mathrm{G})$, yellow $(\mathrm{Y})$, orange $(\mathrm{O})$, and red $(\mathrm{R})$ ELs with peaks at 455, 536, 555, 585, and 628 $\mathrm{nm}$ and CIE coordinates $(0.19,0.20),(0.31,0.47),(0.37,0.52),(0.46,0.48)$, and $(0.55,0.41)$, respectively. The EL spectra showed voltage-independent behavior as well as no temporal degradation that are of great significance for display technology. In the B-OLEDs, $L_{\text {MAX }}$ reached $136 \mathrm{~cd} / \mathrm{m}^{2}$ with $\eta_{\mathrm{c}}$ of $0.084 \mathrm{~cd} / \mathrm{A}$ (Figure $13 \mathrm{~b}-\mathrm{d}$ ).

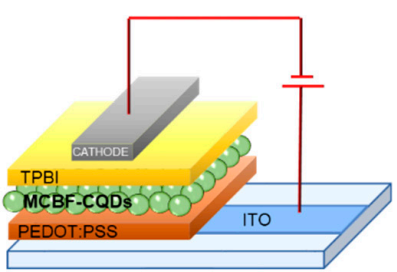

(a)

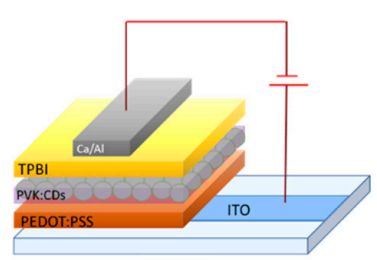

(d)

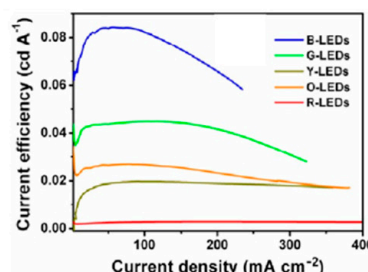

(b)

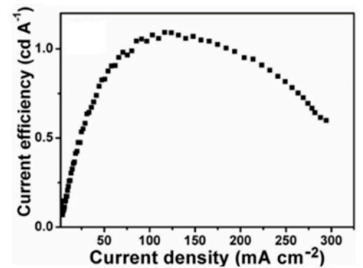

(e)

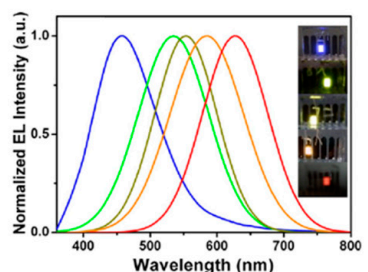

(c)

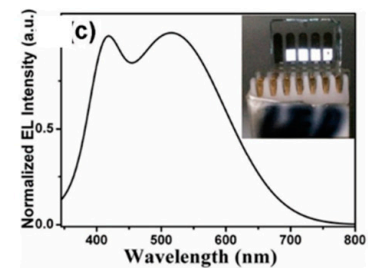

(f)

Figure 13. (a) Schematic representation of the multicolor blue-to-red fluorescent CD (MCBF-CD)-based device architectures, (b) $\eta_{\mathrm{c}}$ vs. J of MCBF-CD-based monochrome electroluminescent OLEDs from blue to red, (c) normalized EL spectra (in the inset is a picture of the working devices), (d) schematic representation of the PVK:MCBF-CD-based device architectures, (e) $\eta_{\mathrm{c}}$ vs. J of PVK:MCBF-CD-based monochrome electroluminescent OLEDs from blue to red, (f) normalized white EL spectra (in the inset is a picture of the working devices), (b,c) reproduced with permission from Reference [65], copyright 2016 Wiley-VCH, and (e,f) reproduced with permission from [14], copyright 2019 American Chemical Society. 
In the devices incorporating a blend of green-emitting $\mathrm{CD}$ into a PVK polymer matrix (5 wt.\% ratio), with ITO/PEDOT:PSS/PVK:MCBF-CDs/TPBI/Ca/Al architecture (Figure 13d), Yuan et al. [65] reached a $L_{\mathrm{MAX}}$ and $\eta_{\mathrm{c}}$ as high as $2050 \mathrm{~cd} / \mathrm{m}^{2}$ and $1.1 \mathrm{~cd} / \mathrm{A}$ with a low turn on voltage $\left(V_{\mathrm{ON}}=3.9 \mathrm{~V}\right)$ (Figure 13e). In the broad EL spectrum, two peaks were identified, centered at 410 and $517 \mathrm{~nm}$ and assigned to PVK and green MCBF-CD emission, respectively (Figure 13f). The CIE coordinate $(0.30,0.33)$, very close to ideal white, resulted from both the energy transfer from PVK to CD and the direct charge trapping on CD.

In 2018, Xu et al. [76] synthesized oleophilic CDs with a PLQY of $41 \%$ by the one-pot microwave carbonization method (Figure 14a) to study the impact of CD aggregation as a limiting factor for the brightness of the CD-LEDs.

(a)

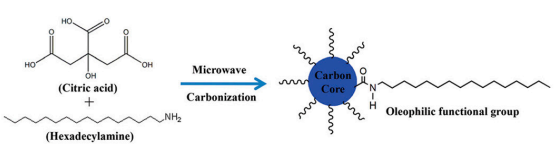

(b)

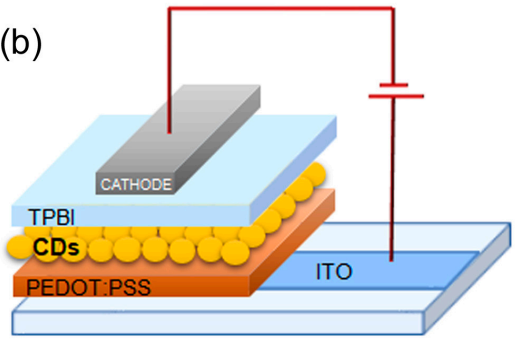

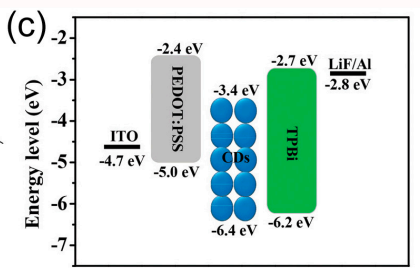

(d)

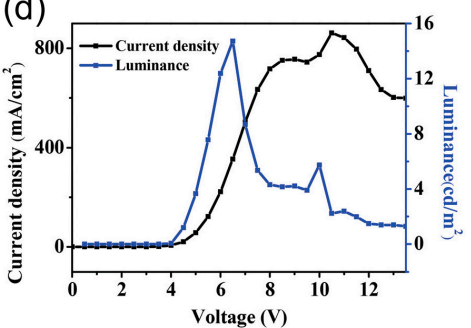

(e)

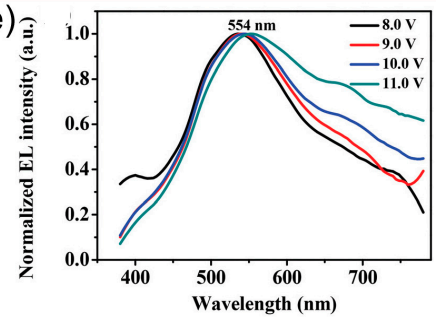

(f)

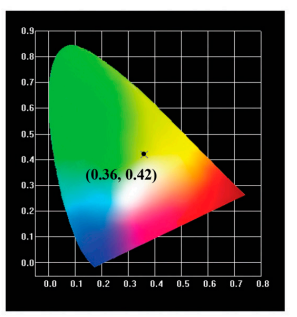

Figure 14. (a) Illustration of the route for the synthesis of CDs, (b) schematic representation of the device architectures, (c) energy level diagram of the CD-LED, (d) $J-L-V$ characteristics curve of the CD-LED, (e) normalized EL spectra of the CD-LED at different driving voltages, (c) current density-voltage-luminance $(J-L-V)$ characteristics curve of the CD-LED, and (f) CIE coordinates of the CD-LED at the working voltage of $10.0 \mathrm{~V}$ : reproduced with permission from [76], copyright 2018 The Royal Society of Chemistry.

They fabricated CD-OLEDs, incorporating a neat $\mathrm{CD}$ active layer, with the simple architecture ITO/PEDOT:PSS/CD/TPBI/LiF/ Al (Figure 14b). The devices featured modest performance (Figure 14c-f), with yellow emission peaked at $554 \mathrm{~nm}, L_{\mathrm{MAX}}$ of $5.7 \mathrm{~cd} / \mathrm{m}^{2}$ at $10 \mathrm{~V}$, and CIE coordinates od $(0.36,0.42)$, most probably because of aggregation of the CDs.

The impact of $\mathrm{CD}$ aggregation on the brightness of CD-OLEDs was studied by $\mathrm{Xu}$ et al. also by blending the CDs in PVK. Yellow and white ELs were observed by tuning the doping concentration of the active layer. The yellow EL, mainly derived from direct carrier trapping, reached $L_{\mathrm{MAX}}$ of $339.5 \mathrm{~cd} / \mathrm{m}^{2}$ with excellent color stability. The white CD-OLEDs exhibited a Color Rendering Index (CRI) value of 83 with CIE coordinates of $(0.29,0.33)$ and high $L_{\mathrm{MAX}}$ of $544.2 \mathrm{~cd} / \mathrm{m}^{2}$. The white EL resulted from contemporary emission from PVK and CDs, and the good brightness was attributed to a suitable balance between holes and electrons in the emitting layer (Figure 15) [76].

In the last 3 years, the research on LEDs based on CDs has increased and focalized, almost exclusively, on CDs dispersed in PVK as an emitting layer. The next two articles discussed below showed that amination could be exploited to improve the performance of devices.

Yuan et al. [77] presented deep-blue light-emitting materials and devices based on CDs that outperform also deep-blue emitting LEDs based on $\mathrm{Cd}^{2+} / \mathrm{Pb}^{2+}$ materials at that time. CDs were synthesized by solvothermal treatment using CA and DAN as precursors. To enable efficient high-color purity, an additional surface amination step using ammonia liquor and hydrazine hydrate under high temperature was performed. This second step, 
decreasing the number of defects of CDs and thus suppressing non-radiative pathways, increases the PLQY up to $70 \%$.

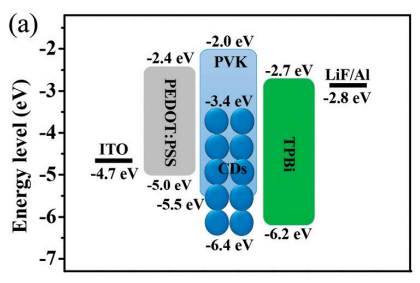

(c)

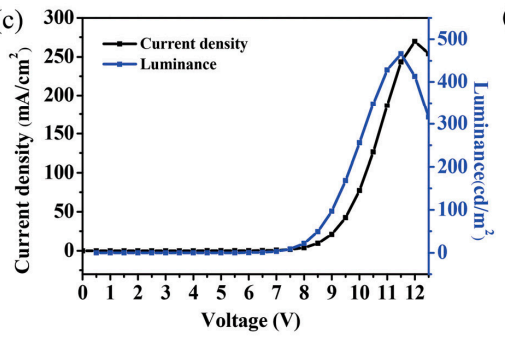

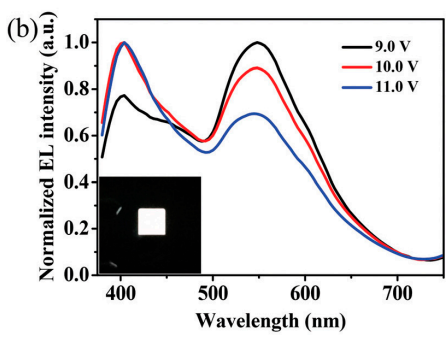

(d)

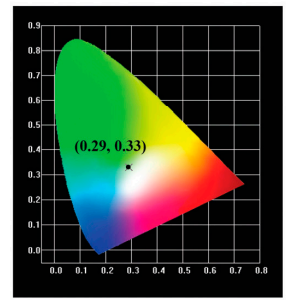

Figure 15. (a) The energy level diagram of the white CD-LED, (b) normalized EL spectra of the white CD-LED at different voltages (in the inset is a photograph of the working device), (c) $J-L-V$ characteristics curve of the white CD-LED, and (d) CIE coordinates at a driving voltage of $11 \mathrm{~V}$ : reproduced with permission from [76], copyright 2018 The Royal Society of Chemistry.

CD-OLEDs were manufactured with the architecture ITO/PEDOT:PSS/TFB/PVK: $\mathrm{CDs} / \mathrm{TPBI} / \mathrm{LiF} / \mathrm{Al}$ (Figure 16a). The corresponding energy level diagram (Figure 16b) shows a mitigation of energy barrier for both electrons and hole injections thanks to the suitable selection of the different functional layers. Atomic force microscope (AFM) measurements confirmed the small roughness of CDs blended PVK film (Figure 16c). The EL spectra remained centered at $440 \mathrm{~nm}$ across the range of voltage explored and are in good agreement with the corresponding PL emission peaks, indicating that an efficient energy transfer from PVK to CDs takes place. $L$ and EQE as functions of $V$ and $J$, respectively, are shown in Figure $16 \mathrm{~d}, \mathrm{e} . L_{\mathrm{MAX}}, \eta_{\mathrm{c}}$, and EQE reached remarkable values of $5240 \mathrm{~cd} / \mathrm{m}^{2}, 2.6 \mathrm{~cd} / \mathrm{A}$, and $4 \%$, respectively.
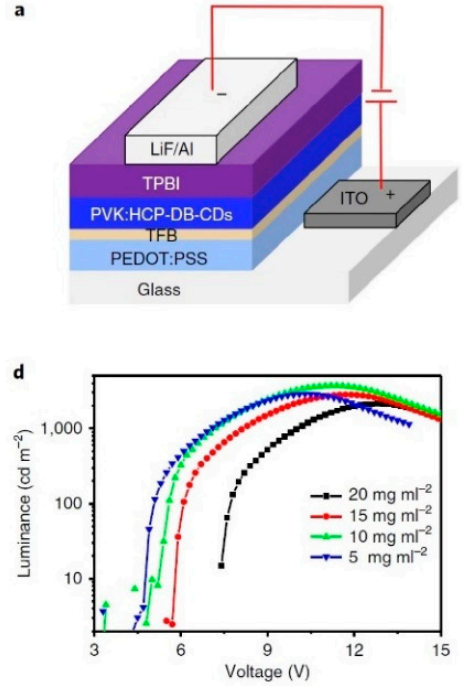
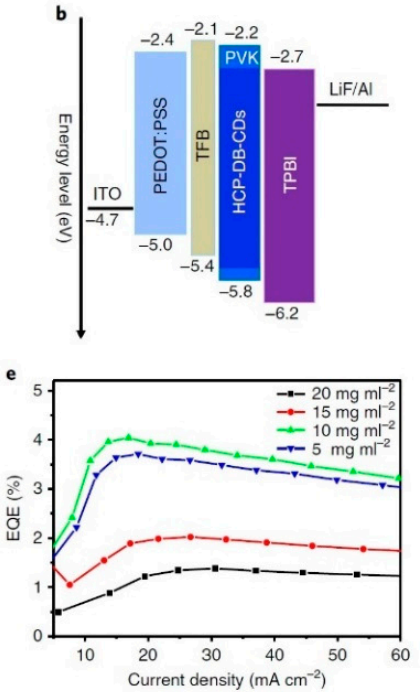
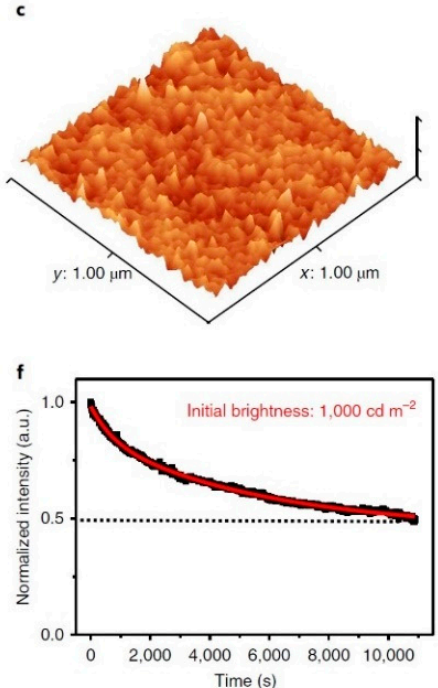

Figure 16. (a) PVK:CD-based device structure, (b) the energy level diagram, (c) the AFM height image of PVK:CD films, (d) the L-V curves, (e) the EQE-J characteristics, and (f) the device stability: Reproduced with permission from [77], copyright 2020 Springer Nature group. 
After operating continuously for $3 \mathrm{~h}$ at $1000 \mathrm{~cd} / \mathrm{m}^{2}$, the OLED retained $50 \%$ of initial luminance (Figure 16f) without evident changes in the EL spectrum.

At the same time, Jia and coworkers [80] demonstrated the effectiveness of the electrondonating group passivation strategy to impart in CD finely tuned properties for their application as emitters in CD-OLEDs. Specifically, they developed three efficient redemissive CDs based on the $\mathrm{N}, \mathrm{N}$-dimethyl- $\left(\mathrm{NMe}_{2}\right), \mathrm{N}, \mathrm{N}$-diethyl-(NEt $\left.\mathrm{N}_{2}\right)$, and $\mathrm{N}, \mathrm{N}$-dipropyl$\left(-\mathrm{NPr}_{2}\right)$ p-phenylenediamine derivatives and obtaining $\mathrm{CD}-\mathrm{NMe}_{2},-\mathrm{NEt}_{2}$, and $-\mathrm{NPr}_{2}$, respectively (Figure 17a), with the aim to fabricate warm-light WOLEDs.

Thanks to theoretical investigations, they revealed that $\mathrm{CD}$ emission originated from the rigid $\pi$-conjugated skeleton structure, while $-\mathrm{NR}_{2}$ passivation played a key role in inducing charge transfer excited state in the $\pi$-conjugated structure to afford high PLQY (up to $86 \%$ ).

Moreover, the polar $-\mathrm{NR}_{2}$ groups are responsible for the good solubility of $\mathrm{CDs}$ in organic solvent and then processability by low-cost spin-coating technique.

Solution-processed OLEDs were fabricated with $9 \mathrm{wt.} \% \mathrm{CDs}-\mathrm{NMe}_{2}$ (WOLEDs 1), $-\mathrm{NEt}_{2}$ (WOLEDs 2), and -NPr (WOLEDs 3) blended in PVK as an emitting layer and the simple architecture ITO/PEDOT:PSS/PolyTPD/blend/TPBI/Ca/Al (Figure 17b). The WOLEDs generated warm-light with two main peaks (434/605, 435/612, and 453/616 $\mathrm{nm}$ for WLEDs 1, 2, and 3, respectively, Figure 17c) attributed to emission from PVK and CDs. The corresponding CIE coordinates and correlated color temperatures were $(0.379$, $0.314) / 3365 \mathrm{~K},(0.383,0.311) / 3168 \mathrm{~K}$, and $(0.388,0.309) / 2987 \mathrm{~K}$. Finally, WOLEDs 1,2 , and 3 displayed voltage-stable EL spectra with a $L_{\mathrm{MAX}}$ in the range of $5248-5909 \mathrm{~cd} / \mathrm{m}^{2}$ and a $\eta_{\mathrm{c}}$ of 3.65-3.85 cd/A (Figure 17d-f).

Yuan et al. [78] recently addressed the issue of broad emission, usually observed in CDs, which limits their application in displays.

They obtained multi-colored narrow bandwidth emission from triangular CDs (T-CDs) synthetized starting from phloroglucinol (PG) (Figure 18A). They demonstrated that the molecular purity and high crystallinity of the triangular CDs are indispensable to obtain high color-purity. The triangular structure and the narrow bandwidth emission allowed for dramatic reduction in electron-phonon coupling.

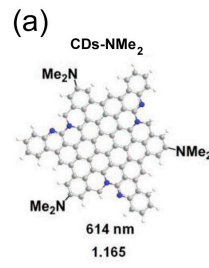

(b)
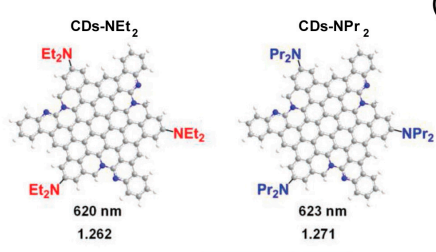

(c)

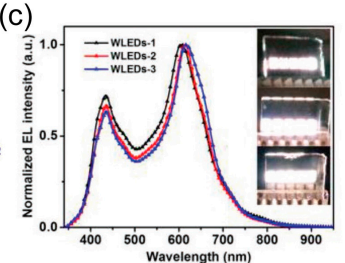

(e)

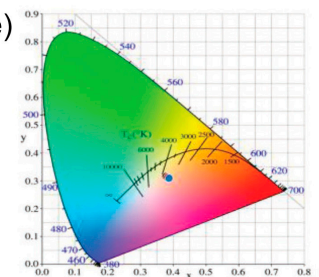

(d)

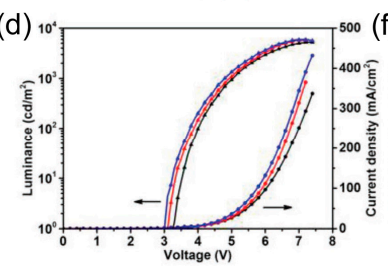

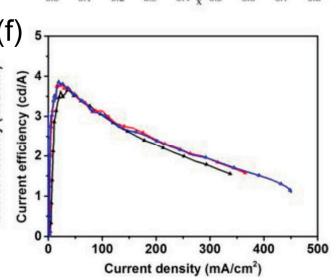

Figure 17. (a) CD structures; (b) architecture of CD-WLEDs; (c) EL spectra of WLEDs 1, 2, and 3 under 7.0 V, (inset, WOLEDs photographs); (d) $J-L-V$ characteristics; (e) CIE coordinates; and (f) $\eta_{\mathrm{c}}$ of WLEDs 1 (black), 2 (red), and 3 (blue): Reproduced with permission from [80], copyright 2019 Wiley-VCH Verlag GmbH \& Co.

The simple structure ITO/PEDOT:PSS/active layer/TPBI/Ca/Al (Figure 18B) was used for fabrication of OLEDs emitting from blue to red with the T-CDs blended in PVK as an active emission layer. The good match between HOMO/LUMO energy levels of T-CDs and PVK ensured the efficient transfer of both electrons and holes from PVK to T-CDs emitter. The multi-colored OLEDs based on the T-CDs demonstrated high color-purity (FWHM of 30-39 nm) peaked at 476, 510, 540, and $602 \mathrm{~nm}$ for B-, G-, Y-, and R-LEDs, 
respectively, a $\eta_{\mathrm{c}}$ of $1.22-5.11 \mathrm{~cd} / \mathrm{A}$, and $\mathrm{L}_{\mathrm{MAX}}$ of $1882-4762 \mathrm{~cd} / \mathrm{m}^{2}$, rivalling the welldeveloped inorganic QD-based LEDs. Finally, the LEDs exhibited outstanding stability, which is of great significance for display technology. See Figure 18B-I

Singh and colleagues [79] fabricated the first flexible OLED (Figure 19a,b) based on CDs employing self-assembled 2D array of CDs embedded in a PVK emission layer. The flexible device was switched on at $4.3 \mathrm{~V}$ and exhibited a blue/cyan emission peaked at about $500 \mathrm{~nm}$ (comparable to PL emission, Figure 19c) with $L_{\mathrm{MAX}}$ of $350 \mathrm{~cd} / \mathrm{m}^{2}$ and $\eta_{\mathrm{c}}$ of $0.22 \mathrm{~cd} / \mathrm{A}$ (Figure 19d,e), whereas the corresponding OLED device based on the rigid glass substrate featured a $L_{\mathrm{MAX}}$ of $700 \mathrm{~cd} / \mathrm{m}^{2}$ and $\eta_{\mathrm{c}}$ of $0.27 \mathrm{~cd} / \mathrm{A}$. Figure $19 \mathrm{f}$ shows the CD 2D island in the emitter layer.
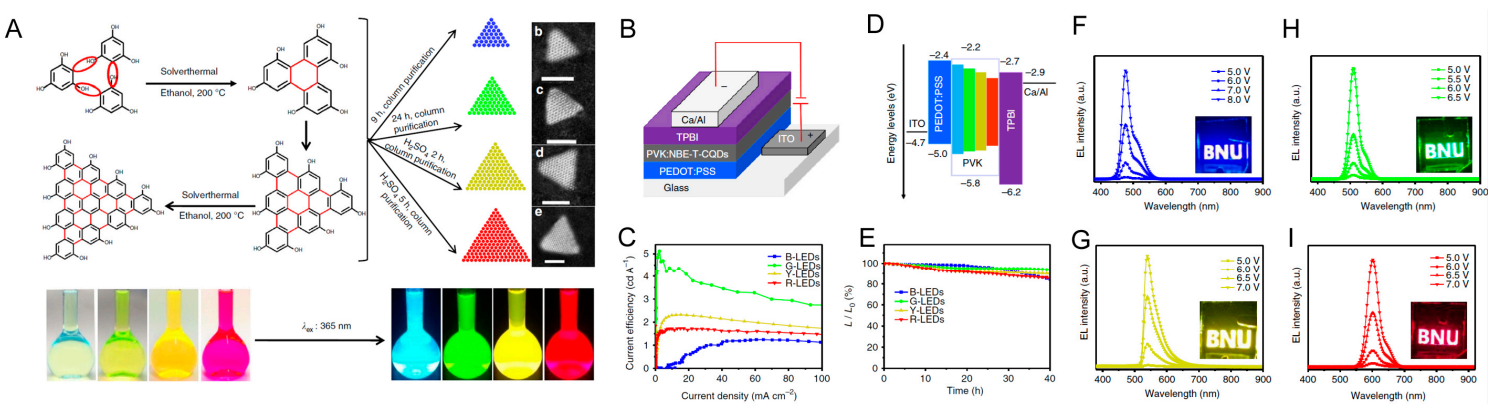

Figure 18. (A) Synthesis route of the T-CQDs by solvothermal treatment of PG triangulogen, with photographs of the T-CQD ethanol solution under daylight (left) and fluorescence images under UV light (excited at $365 \mathrm{~nm}$ ) (right) included; (B) the device structure; (C) the current efficiency versus current density; (D) the energy level diagram of the T-CQD-based LEDs; and (E) the stability plots of the B-, G-, Y-, and R-LED. EL spectra of the B- (F), G- (H), Y- (G), and R-LEDs (I) at different bias voltage, respectively (the insets are the operation photographs of the B-, G-, Y-, and R-LEDs with the logo of BNU). Reproduced with permission from Reference [78], copyright 2019 Springer Nature group.

(a)

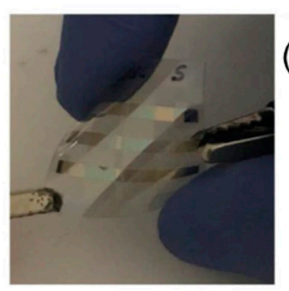

(d)
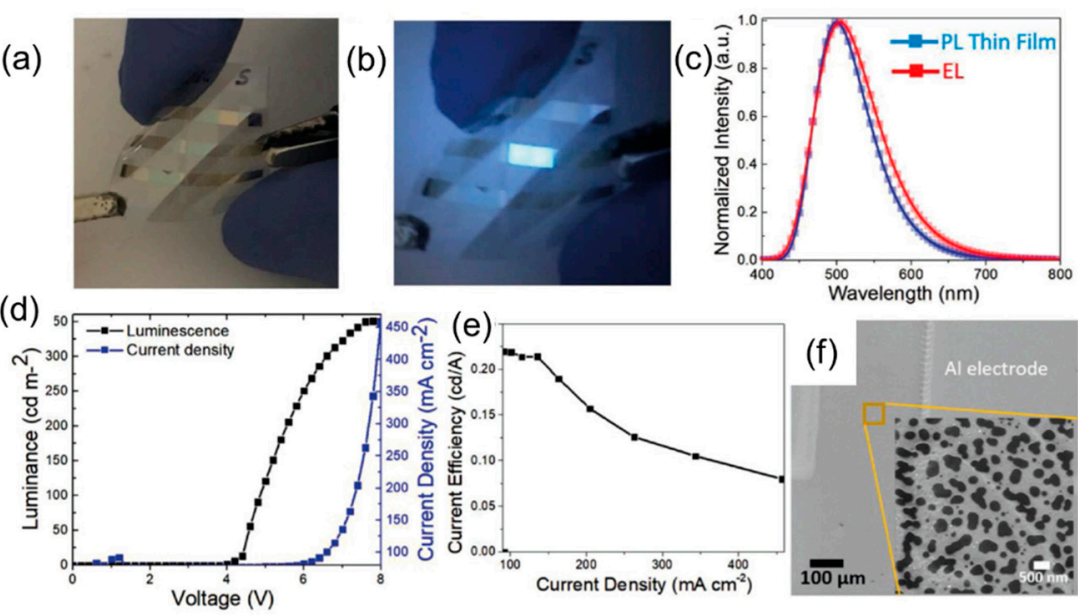

(e)

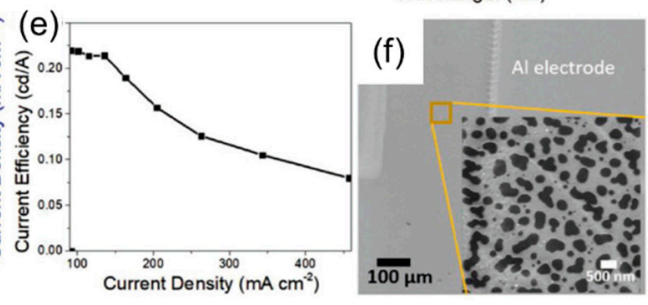

Figure 19. Picture of a flexible device: (a) off mode and (b) on mode; (c) the normalized EL spectra of the device and solid-state PL of a thin film; (d) $J-L-V$ characteristic of the device; (e) current efficiency versus current density; and (f) CD 2D islands in the emitter layer: Reproduced with permission from [79], copyright 2020 Wiley-VCH Verlag GmbH \& Co.

The host-guest energy transfer as the main mechanism for CD emission was exploited by $\mathrm{Xu}$ et al. [81] for the fabrication of solution-processed blue CD-LEDs with ultrahigh brightness. Oleophylic CDs with a PLQY of $41 \%$ were obtained using an anhydrous citric acid as carbon precursor and hexadecylamine as passivation agent by the one-step microwave carbonization method. CDs with different doping concentrations were blended with PVK and incorporated into a simple and PEDOT-free device architecture ITO/PVK:CDs/TPBI/LiF/Al (Figure 20a). The EL spectra of devices were dominated by the $474 \mathrm{~nm}$ CD emission peak with a contribution from a PVK at around $410 \mathrm{~nm}$. When 
the doping concentration was higher than $25 \mathrm{wt} . \%$, a progressive weakening of the PVK contribution in favor of an enhanced CD emission was observed. For the $30 \mathrm{wt} . \%$ doping ratio, the $L_{\mathrm{MAX}}$ reached $569.8 \mathrm{~cd} / \mathrm{m}^{2}$ at a driving voltage of $12.5 \mathrm{~V}$, with CIE coordinated at $(0.22,0.27)$ located in the blue light region (Figure 20b). Also, in this case, the longchain passivating ligands on the oleophylic $\mathrm{CD}$ surfaces were responsible for the unideal transporting performance that limited the device efficiencies. However, it should also be considered that the devices do not contain the commonly employed PEDOT:PSS layer.

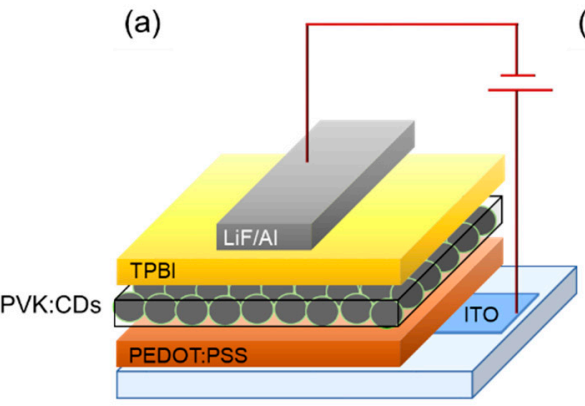

(b)

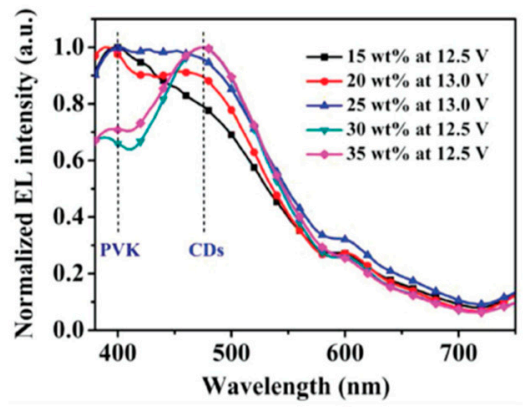

Figure 20. (a) Device architecture and (b) normalized EL spectra for different CD-doped devices: Reproduced with permission from [81], copyright 2020 Wiley-VCH Verlag GmbH \& Co.

\subsection{CDs as Charge Regulating Interlayer}

The possibility to tune the CD's energy levels and intrinsic charge carrier transport enables an alternative use of $\mathrm{CD}$ besides incorporation as an emitting layer. In fact, the following paragraph demonstrates that CDs, employed as an interlayer at the electrode interface (for this reason, they are called interfacial layers or charge regulating layers) in devices based on different class of emitters, may improve the overall performance of LEDs. We report examples in which the CD layer was incorporated both as ETL and HTL in either direct or inverted LED architectures (Figure 7).

In 2017, Park et al. [84] explored the possibility to enhance the performance of nanocrystal LEDs (NC-LEDS) based on quantum dot active layers. NC-LEDs typically take advantage of the incorporation of organic or inorganic interfacial layers as charge regulators to ensure charge balancing and high performance [87]. They investigated the role played by $\mathrm{CD} \mathrm{N}$-doped interlayers inserted by spin-coating between the PVK (used as HTL) and the core/shell CdSe/CdS quantum dots (QDs)-based emitting layer [88,89]. In fact, QD-LEDs basically consisted of a multilayer architecture ITO/PEDOT:PSS/PVK/ with or without $\mathrm{N}-\mathrm{CD} / \mathrm{QD} / \mathrm{ZnO} / \mathrm{Al}$ (types A and B, Figure 21a). They showed that CD HTL decreased the barrier height for hole injection, thus leading to more charge carrier balance within the emitting layer. Moreover, they demonstrated that the CD interlayer acted as a resonant energy donor layer to the QD layer.

Both type A and B devices exhibited good electrical rectification, but the leakage current of type A QD-LEDs was significantly suppressed by inserting the N-CD layer (see lower $\mathrm{J}$ for type A devices with respect to type $\mathrm{B}$ ones in the ohmic range below $0.5 \mathrm{~V}$ in Figure 21b,c). Noteworthily, the $L_{\mathrm{MAX}}$ observed in LED incorporating CDs outperformed type B LEDs, showing 3500 and $20 \mathrm{~cd} / \mathrm{m}^{2}$, and the $\eta_{\mathrm{c}}$ were 0.63 and $0.044 \mathrm{~cd} / \mathrm{A}$, respectively (Figure 21d,e). The EL of both types of LEDs was dominated by the emission peak at $622 \mathrm{~nm}$ under applied voltage $>4 \mathrm{~V}$ (Figure 21f) with CIE coordinates $(0.66,0.33)$ corresponding to the highly pure red emission (Figure 21g). 

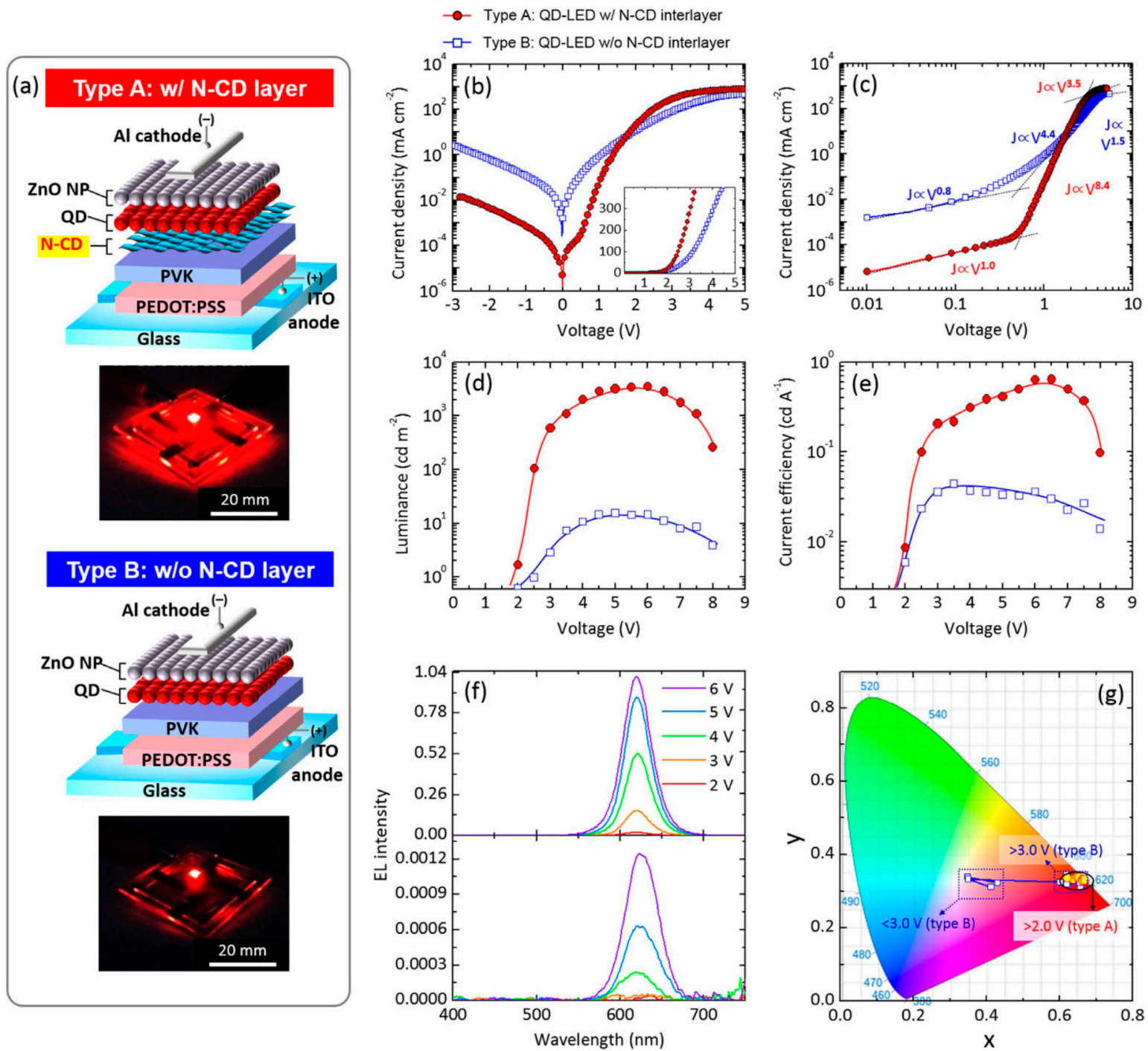

Figure 21. (a) Structures of solution-processed quantum dots (QD)-LEDs, with photographs of red emission from both types of QD-LEDs reported; (b) $J-V$ characteristic curves, with an inset plotted in a linear scale at forward applied voltages; (c) $J-V$ characteristic curves plotted on double-logarithmic axes; (d) luminance and (e) current efficiency plotted as a function of applied voltage; (f) EL spectra of the N-CD-inserted QD-LED (upper panel) and the control QD-LED (lower panel) at diverse applied voltages; and (g) CIE coordinates of EL emission colors measured at various applied bias voltages of 2.0-8.0 V: Reproduced with permission from [84], copyright 2019 Springer Nature group.

In a very recently publication, Paulo-Mirasol et al. [90] described the use CDs as HTL but in an inverted LED architecture. They synthetized four N-doped CDs by citric acid as a precursor of carbon skeleton and p-phenylenediamine, EDA, urea, and HDA as precursors of a capping ligand and showed that the nature of the capping ligand influences directly the optoelectronic properties of CDs (Table 2). The architecture of the device consisted of a $\mathrm{ZnO}$ nanoparticle layer directly deposited on the ITO of an emissive conjugated polymer, the well-known and commercially available poly (9,9-dioctylfluorene-alt- benzothiazole or F8BT, and of the CDs (Figure 22A) as HTL. The devices were completed by Au anode. 
Table 2. Summary of the most relevant parameters of devices from Reference [90], including values obtained for a control device without hole transporting layer (HTL).

\begin{tabular}{cccc}
\hline $\begin{array}{c}\text { Hole Transport } \\
\text { Materials }\end{array}$ & $\begin{array}{c}\text { Capping Ligand } \\
\text { Hole Mobility }\end{array}$ & $\boldsymbol{L}_{\mathbf{M A X}}\left(\mathbf{c d} / \mathbf{m}^{\mathbf{2}}\right)$ & $\boldsymbol{\eta}_{\mathbf{c}}(\mathbf{c d} / \mathbf{A})$ \\
\hline C-Dots-EDA & $2.41 \pm 0.60$ & 70 & $2 \times 10^{-3}$ \\
C-Dots-PDA & $1.5 \pm 0.47$ & 13 & $9 \times 10^{-4}$ \\
C-Dots-HDA & $85.4 \pm 1.7$ & 174 & $8 \times 10^{-4}$ \\
C-Dots-Urea & $2.92 \pm 0.32$ & 146 & $2 \times 10^{-3}$ \\
No HTM (control) & - & 2 & $5 \times 10^{-4}$ \\
\hline
\end{tabular}

a space charge limited current hole mobility measured in hole-only devices.
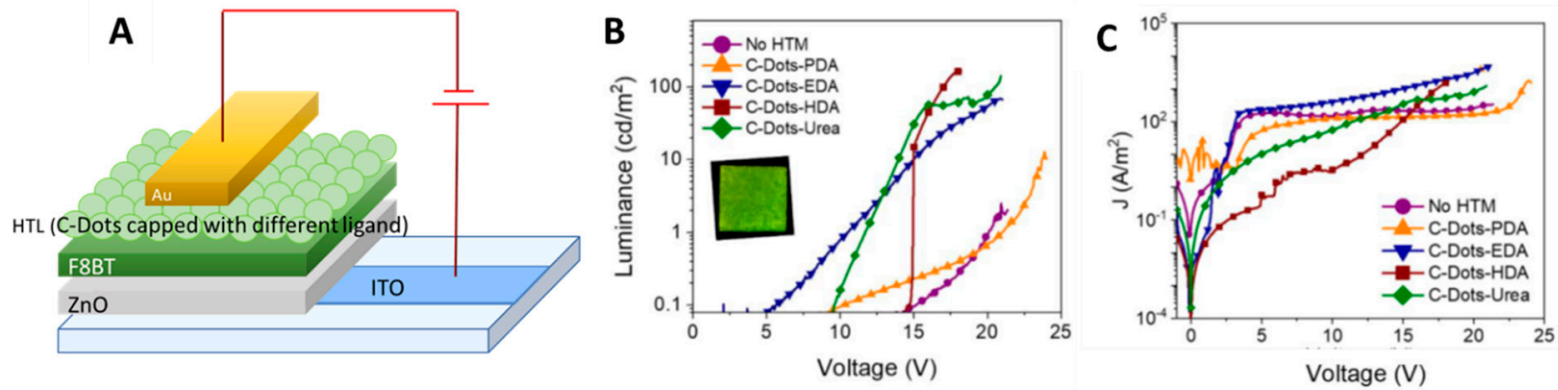

Figure 22. (A) Device architecture, (B) luminance vs. applied bias (the inset shows a picture of a working device), and (C) current density versus applied bias for the inverted LEDs prepared using the CDs in the selective contact for holes: reproduced with permission from Reference [90], copyright 2019 American Chemical Society.

The LEDs displayed moderate $L$ values but were always clearly superior to the control CD-free device (Figure 22B,C). In the case of EDA capping, the $V_{\mathrm{ON}}$ was very low, which indicates the existence of an excellent charge injection capability. On the other hand, devices prepared with urea and HDA CDs showed the highest $L$, as summarized in Table 2 .

Alam et al. [83] reported the use of CDs synthesized with a one-step hydrothermal process using the banana leaf precursor as the ETL in direct architecture LEDs with polyfluorene derivative as the emitting layer (Figure 23a,b). The introduction of CD as the ETL reduces the energy barrier for electron injection, which in turn lowered the $V_{\mathrm{ON}}$. The EL spectra showed dominant peaks typical of PFO but slightly red-shifted compared to that in the literature.

Zang et al. [82] demonstrated that stable, abundant, and easy-to-synthesize CDs are suitable as solution processable thin transparent films, serving as the cathode surface modifier in inverted LED architecture. This CD ETL minimized the charge injection/extraction energy barrier, improved the interface contact property, and smoothed the electron transport pathways in various optoelectronic devices such as perovskite solar cells and QD-LEDs. A series of CDs with varying content of either amine or carboxyl groups at their surface were synthesized using varying ratios of common precursors CA and EDA. Thanks to a film consisting in a blend of $\mathrm{CDs}$ in $\mathrm{ZnO}$, the work-function (WF) of commonly used ITO substrates was modified over a broad range to become suitable as electron injection electrode in the inverted device architecture (Figure 24a,b). Specifically, CD modifiers with abundant amine groups reduced the ITO's WF from 4.64 to $3.42 \mathrm{eV}$, while those with abundant carboxyl groups increased it to $4.99 \mathrm{eV}$. They manufactured the inverted QD-LED architecture based on $\mathrm{CsPbI}_{3}$ emitters. The EQE increased from $4.8 \%$ to $10.3 \%$ and the $L_{\mathrm{MAX}}$ increased from 951 to $1605 \mathrm{~cd} / \mathrm{m}^{2}$ thanks to incorporation of the CD layer and in the same way, the EQE of CdSe/ZnS QD-LEDs increased from $8.1 \%$ to $21.9 \%$ and $\eta_{\mathrm{c}}$ increased from 34.7 at $93.8 \mathrm{~cd} / \mathrm{A}$ (Figure $24 \mathrm{c}-\mathrm{f}$ ). 
(a)

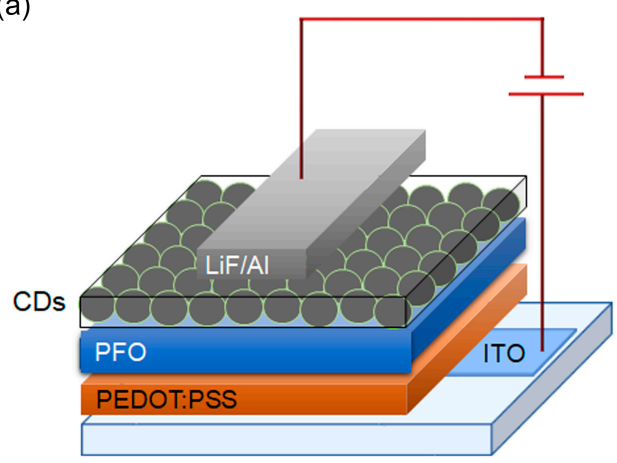

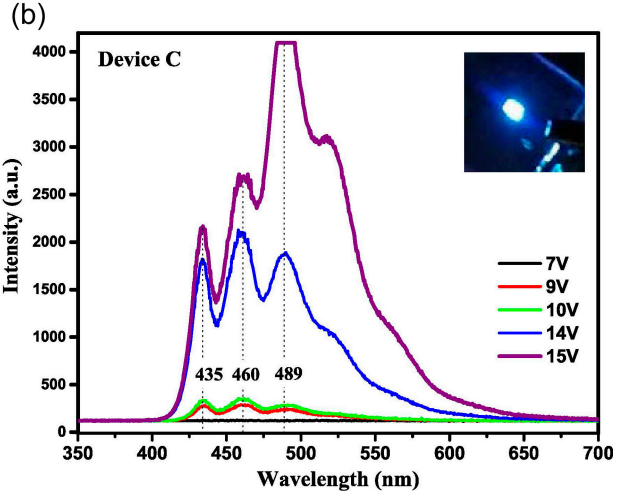

Figure 23. (a) Scheme of the device architecture and (b) EL spectra as a function of operating voltage: Reproduced with permission from [83], copyright 2019 Wiley-VCH Verlag GmbH \& Co.
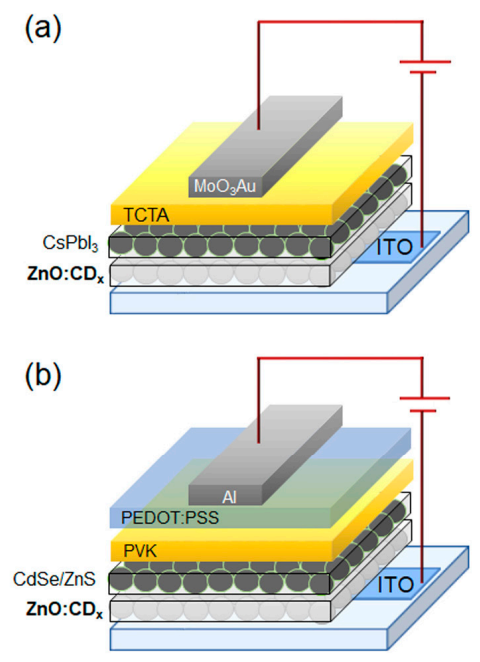

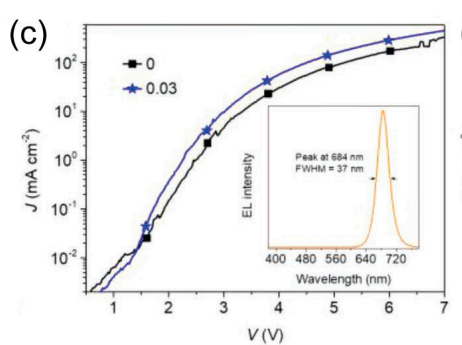

(d)

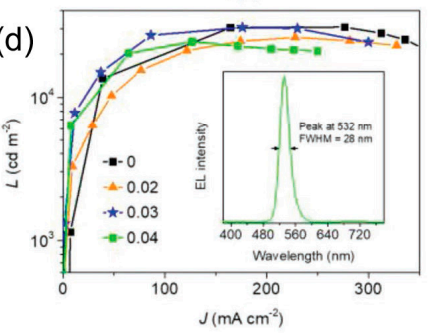

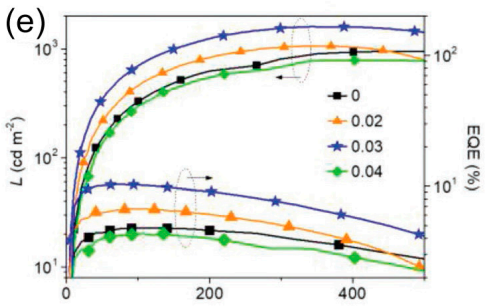

$J\left(\mathrm{~mA} \mathrm{~cm}^{-2}\right)$

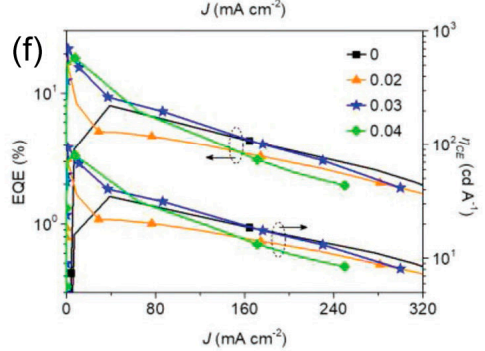

Figure 24. (a) $\mathrm{CsPbI}_{3}$ and (b) $\mathrm{CdSe} / \mathrm{ZnS}$ QD-LED device architectures; (c) J-V of $\mathrm{CsPbI}_{3}$ QD-LEDs with or without CDs (concentration $0.03 \mathrm{mg} / \mathrm{mL}$ in $\mathrm{ZnO}$ and $\mathrm{CD}_{x}$ being molar ratios of the $\mathrm{CA}$ and EDA precursors) interface modifier, with the EL spectrum of the LED employing the CD $(0.03 \mathrm{mg} / \mathrm{mL})$ modifier given as an inset; (d) L-J of CdSe/ZnS QD-LEDs modified with different concentrations of $\mathrm{CDs}$ as given on the frame (in $\mathrm{mg} / \mathrm{mL}$ ), with the EL spectrum of the LED employing the CDs (concentration $0.03 \mathrm{mg} / \mathrm{mL}$ ) modifier given as an inset; (e) $\mathrm{L}$ and EQE versus J of $\mathrm{CsPbI}_{3}$ QD-LEDs modified with different concentrations of $\mathrm{CD}_{0.33}$ as given on the frame (in $\mathrm{mg} / \mathrm{mL}$ ); and (f) EQE and $\eta_{\mathrm{c}}$ versus J of CdSe/ZnS QD-LEDs with or without CD modifiers introduced at different concentrations (in $\mathrm{mg} / \mathrm{mL}$ ) provided on the frame: Reproduced with permission from [82], copyright 2019 WILEY-VCH Verlag GmbH \& Co.

The proposed approach may hold true for CDs with other surface functional groups, which guides us toward more ideal interface materials, offering chances to lower the production costs of various solution-processed optoelectronic devices with an improved performance.

\section{Summary and Outlook}

CDs are materials with a great potential from multiple points of view. In fact, despite being relatively young materials, the discovery of which is placed between 2004 and 2006, their development has already led to particularly encouraging results in many disciplines including biosensing, photonics, and optoelectronics.

The interest in this class of materials is both academic and applicative. In fact, numerous efforts have been made to understand and modulate their chemical and physical properties, and although different mechanisms have been highlighted, much remains to be 
done, especially in reproducibility and in the deep understanding of their size, shape, and composition/doping property dependence.

With regard to their application in OLEDs, as reported here, they have been used both as active layers and as charge regulation layers.

CDs have been used as active layers both dispersed in the matrix to avoid aggregation quenching and as a neat film, leading to increasingly encouraging results mostly when their surface was passivated by a hexadecylamine (HDA) agent [71,79].

Recently, CDs have been tested as a charge regulating layer (both for holes and for electrons), in either direct or inverted device's architectures, highlighting their great versatility linked to the huge number of possible modifications, which, as we have pointed out, are related to composition, shape, size, and surface groups. Importantly, CDs used as ETLs in OLED with direct architecture were synthetized with the one-step hydrothermal process using banana leaves as raw material.

In our opinion, the importance of these materials consists in the possibility of declining them for the concept of safe-by-design, which is substantially at the basis of circular economy.

To promote sustainability in the electronics industry, a paradigm shift needs to occur in economic practices from linear to circular. According to the Ellen McArthur Foundation, new electronics must be designed for sustainability from the get-go [91].

Technical performance is the driving force for not only the design but also the use of sustainable precursor (from waste or renewable materials); biodegradability, toxicity, synthetic methodology, and production of toxic waste are only some of the key parameters to be taken into consideration.

In this perspective, although CDs are currently still very far from the performance of other active materials commonly used in LED and OLED such as metallic quantum dots or organic semiconductors, in a circular perspective, they are already able to meet some fundamental requirements.

For this reason, we hope that this review can offer a contribution and be a source of inspiration for the transition towards "circular organic electronics".

Author Contributions: Conceptualization, U.G. and M.P.; writing—original draft preparation, P.L.; writing-review and editing, M.P. and U.G.; funding acquisition, M.P. and U.G. All authors have read and agreed to the published version of the manuscript.

Funding: This work was carried out with the financial support of Regione Lombardia Project "Piattaforma tecnologica per lo sviluppo di sonde innovative in ambito biomedicale" (ID 244356). U.G. thanks the MIUR-PRIN project Prot. 20172M3K5N.

Conflicts of Interest: The authors declare no conflict of interest.

\section{References}

1. Baldé, C.P.; Forti, V.; Gray, V.; Kuehr, R.; Stegmann, P.; International Telecommunication Union; United Nations University; International Solid Waste Association. The Global E-Waste Monitor 2017: Quantities, Flows, and Resources; United Nations University: Tokyo, Japan; International Telecommunication Union: Geneva, Switzerland; International Solid Waste Association: Rotterdam, The Netherlands, 2017; ISBN 9789280890532.

2. Ostroverkhova, O. Organic Optoelectronic Materials: Mechanisms and Applications. Chem. Rev. 2016, 116, 13279-13412. [CrossRef]

3. Forrest, S.R.; Thompson, M.E. Introduction: Organic electronics and optoelectronics. Chem. Rev. 2007, 107, 923-925. [CrossRef]

4. Hadziioannou, G.; Malliaras, G.G.M. Semiconducting Polymers: Chemistry, Physics and Engineering, 2nd Edition, Two-Volume Set; Hadziioannou, G., Malliaras, G.G.M., Eds.; Wiley: Hoboken, NJ, USA, 2006; ISBN 978-3-527-31271-9.

5. Zvezdin, A.; Di Mauro, E.; Rho, D.; Santato, C.; Khalil, M. En route toward sustainable organic electronics. MRS Energy Sustain. 2020, 7. [CrossRef]

6. Giovanella, U.; Betti, P.; Bolognesi, A.; Destri, S.; Melucci, M.; Pasini, M.; Porzio, W.; Botta, C. Core-type polyfluorene-based copolymers for low-cost light-emitting technologies. Org. Electron. 2010, 11, 2012-2018. [CrossRef]

7. Irimia-Vladu, M. "Green" electronics: Biodegradable and biocompatible materials and devices for sustainable future. Chem. Soc. Rev. 2014, 43, 588-610. [CrossRef] 
8. Yan, L.; Zhao, F.; Wang, J.; Zu, Y.; Gu, Z.; Zhao, Y. A Safe-by-Design Strategy towards Safer Nanomaterials in Nanomedicines. Adv. Mater. 2019, 31, 1805391. [CrossRef]

9. Gomulya, W.; Derenskyi, V.; Kozma, E.; Pasini, M.; Loi, M.A. Polyazines and polyazomethines with didodecylthiophene units for selective dispersion of semiconducting single-walled carbon nanotubes. Adv. Funct. Mater. 2015, 25, 5858-5864. [CrossRef]

10. Xu, X.; Ray, R.; Gu, Y.; Ploehn, H.J.; Gearheart, L.; Raker, K.; Scrivens, W.A. Electrophoretic analysis and purification of fluorescent single-walled carbon nanotube fragments. J. Am. Chem. Soc. 2004, 126, 12736-12737. [CrossRef]

11. Sun, Y.P.; Zhou, B.; Lin, Y.; Wang, W.; Fernando, K.A.S.; Pathak, P.; Meziani, M.J.; Harruff, B.A.; Wang, X.; Wang, H.; et al. Quantum-sized carbon dots for bright and colorful photoluminescence. J. Am. Chem. Soc. 2006, 128, 7756-7757. [CrossRef]

12. Xiao, L.; Sun, H. Novel properties and applications of carbon nanodots. Nanoscale Horiz. 2018, 3, 565-597. [CrossRef]

13. Li, X.; Rui, M.; Song, J.; Shen, Z.; Zeng, H. Carbon and graphene quantum dots for optoelectronic and energy devices: A review. Adv. Funct. Mater. 2015, 25, 4929-4947. [CrossRef]

14. Semeniuk, M.; Yi, Z.; Poursorkhabi, V.; Tjong, J.; Jaffer, S.; Lu, Z.H.; Sain, M. Future perspectives and review on organic carbon dots in electronic applications. ACS Nano 2019, 13, 6224-6255. [CrossRef]

15. Campuzano, S.; Yáñez-Sedeño, P.; Pingarrón, J.M. Carbon dots and graphene quantum dots in electrochemical biosensing. Nanomaterials 2019, 9, 634. [CrossRef]

16. Liu, M.L.; Chen, B.B.; Li, C.M.; Huang, C.Z. Carbon dots: Synthesis, formation mechanism, fluorescence origin and sensing applications. Green Chem. 2019, 21, 449-471. [CrossRef]

17. Wang, Y.; Hu, A. Carbon quantum dots: Synthesis, properties and applications. J. Mater. Chem. C 2014, 2, 6921-6939. [CrossRef]

18. Gayen, B.; Palchoudhury, S.; Chowdhury, J. Carbon dots: A mystic star in the world of nanoscience. J. Nanomater. 2019, 2019, 3451307. [CrossRef]

19. Chan, K.K.; Yap, S.H.K.; Yong, K.T. Biogreen synthesis of carbon dots for biotechnology and nanomedicine applications. Nano-Micro Lett. 2018, 10, 72. [CrossRef]

20. Zuo, J.; Jiang, T.; Zhao, X.; Xiong, X.; Xiao, S.; Zhu, Z. Preparation and application of fluorescent carbon dots. J. Nanomater. 2015, 2015. [CrossRef]

21. Pal, A.; Sk, M.P.; Chattopadhyay, A. Recent advances in crystalline carbon dots for superior application potential. Mater. Adv. 2020, 1, 525-553. [CrossRef]

22. Wang, L.; Li, W.; Yin, L.; Liu, Y.; Guo, H.; Lai, J.; Han, Y.; Li, G.; Li, M.; Zhang, J.; et al. Full-color fluorescent carbon quantum dots. Sci. Adv. 2020, 6, eabb6772. [CrossRef] [PubMed]

23. Li, X.; Wang, H.; Shimizu, Y.; Pyatenko, A.; Kawaguchi, K.; Koshizaki, N. Preparation of carbon quantum dots with tunable photoluminescence by rapid laser passivation in ordinary organic solvents. Chem. Commun. 2011, 47, 932-934. [CrossRef] [PubMed]

24. Yang, Z.C.; Wang, M.; Yong, A.M.; Wong, S.Y.; Zhang, X.H.; Tan, H.; Chang, A.Y.; Li, X.; Wang, J. Intrinsically fluorescent carbon dots with tunable emission derived from hydrothermal treatment of glucose in the presence of monopotassium phosphate. Chem. Commun. 2011, 47, 11615-11617. [CrossRef] [PubMed]

25. Hu, S.; Liu, J.; Yang, J.; Wang, Y.; Cao, S. Laser synthesis and size tailor of carbon quantum dots. J. Nanoparticle Res. 2011, 13, 7247-7252. [CrossRef]

26. Tarasenka, N.; Stupak, A.; Tarasenko, N.; Chakrabarti, S.; Mariotti, D. Structure and optical properties of carbon nanoparticles generated by laser treatment of graphite in liquids. ChemPhysChem 2017, 18, 1074-1083. [CrossRef] [PubMed]

27. De, B.; Karak, N. A green and facile approach for the synthesis of water soluble fluorescent carbon dots from banana juice. RSC Adv. 2013, 3, 8286-8290. [CrossRef]

28. Zhu, S.; Meng, Q.; Wang, L.; Zhang, J.; Song, Y.; Jin, H.; Zhang, K.; Sun, H.; Wang, H.; Yang, B. Highly photoluminescent carbon dots for multicolor patterning, sensors, and bioimaging. Angew. Chemie Int. Ed. 2013, 52, 3953-3957. [CrossRef]

29. Dong, Y.; Pang, H.; Yang, H.B.; Guo, C.; Shao, J.; Chi, Y.; Li, C.M.; Yu, T. Carbon-based dots co-doped with nitrogen and sulfur for high quantum yield and excitation-independent emission. Angew. Chemie Int. Ed. 2013, 52, 7800-7804. [CrossRef]

30. Chen, Y.; Lian, H.; Wei, Y.; He, X.; Chen, Y.; Wang, B.; Zeng, Q.; Lin, J. Concentration-induced multi-colored emissions in carbon dots: Origination from triple fluorescent centers. Nanoscale 2018, 10, 6734-6743. [CrossRef]

31. Ehrat, F.; Bhattacharyya, S.; Schneider, J.; Löf, A.; Wyrwich, R.; Rogach, A.L.; Stolarczyk, J.K.; Urban, A.S.; Feldmann, J. Tracking the source of carbon dot photoluminescence: Aromatic domains versus molecular fluorophores. Nano Lett. 2017, 17, 7710-7716. [CrossRef]

32. Bao, L.; Liu, C.; Zhang, Z.L.; Pang, D.W. Photoluminescence-tunable carbon nanodots: Surface-state energy-gap tuning. Adv. Mater. 2015, 27, 1663-1667. [CrossRef]

33. Zhang, J.; Su, Z.C.; Cui, Y.; Hu, G.; Tang, Y.L.; Gan, Z.X.; Yang, L.; Lao, X.Z.; Bao, Y.T.; Xu, S.J. The roles of self-absorption and radiative energy transfer in photoluminescence of $\mathrm{N}$-doped carbon nanodots in solution. AIP Adv. 2019, 9, 035135. [CrossRef]

34. Khan, S.; Gupta, A.; Verma, N.C.; Nandi, C.K. Time-resolved emission reveals ensemble of emissive states as the origin of multicolor fluorescence in carbon dots. Nano Lett. 2015, 15, 8300-8305. [CrossRef] [PubMed]

35. Zhu, S.; Zhang, J.; Liu, X.; Li, B.; Wang, X.; Tang, S.; Meng, Q.; Li, Y.; Shi, C.; Hu, R.; et al. Graphene quantum dots with controllable surface oxidation, tunable fluorescence and up-conversion emission. RSC Adv. 2012, 2, 2717. [CrossRef]

36. Wang, X.; Qu, K.; Xu, B.; Ren, J.; Qu, X. Microwave assisted one-step green synthesis of cell-permeable multicolor photoluminescent carbon dots without surface passivation reagents. J. Mater. Chem. 2011, 21, 2445. [CrossRef] 
37. Yang, S.T.; Wang, X.; Wang, H.; Lu, F.; Luo, P.G.; Cao, L.; Meziani, M.J.; Liu, J.H.; Liu, Y.; Chen, M.; et al. Carbon dots as nontoxic and high-performance fluorescence imaging agents. J. Phys. Chem. C 2009, 113, 18110-18114. [CrossRef] [PubMed]

38. Wang, K.; Gao, Z.; Gao, G.; Wo, Y.; Wang, Y.; Shen, G.; Cui, D. Systematic safety evaluation on photoluminescent carbon dots. Nanoscale Res. Lett. 2013, 8, 1-9. [CrossRef]

39. Dias, C.; Vasimalai, N.; Sárria, M.P.; Pinheiro, I.; Vilas-Boas, V.; Peixoto, J.; Espiña, B. Biocompatibility and bioimaging potential of fruit-based carbon dots. Nanomaterials 2019, 9, 199. [CrossRef]

40. Sendão, R.; de Yuso, M.D.V.M.; Algarra, M.; da Silva, J.C.E.; da Silva, L.P. Comparative life cycle assessment of bottom-up synthesis routes for carbon dots derived from citric acid and urea. J. Clean. Prod. 2020, 254. [CrossRef]

41. Zhu, S.; Song, Y.; Zhao, X.; Shao, J.; Zhang, J.; Yang, B. The photoluminescence mechanism in carbon dots (graphene quantum dots, carbon nanodots, and polymer dots): Current state and future perspective. Nano Res. 2015, 8, 355-381. [CrossRef]

42. Giovanella, U.; Pasini, M.; Botta, C. Organic Light-Emitting Diodes (OLEDs): Working Principles and Device Technology; Springer: Cham, Switzerland, 2016; pp. 145-196.

43. Squeo, B.M.; Pasini, M. BODIPY platform: A tunable tool for green to NIR OLEDs. Supramol. Chem. 2020, 32, 56-70. [CrossRef]

44. De Medeiros, T.V.; Manioudakis, J.; Noun, F.; Macairan, J.R.; Victoria, F.; Naccache, R. Microwave-assisted synthesis of carbon dots and their applications. J. Mater. Chem. C 2019, 7, 7175-7195. [CrossRef]

45. Huang, C.C.; Hung, Y.S.; Weng, Y.M.; Chen, W.; Lai, Y.S. Sustainable development of carbon nanodots technology: Natural products as a carbon source and applications to food safety. Trends Food Sci. Technol. 2019, 86, 144-152. [CrossRef]

46. Ludmerczki, R.; Mura, S.; Carbonaro, C.M.; Mandity, I.M.; Carraro, M.; Senes, N.; Garroni, S.; Granozzi, G.; Calvillo, L.; Marras, S.; et al. Carbon dots from citric acid and its intermediates formed by thermal decomposition. Chem. A Eur. J. 2019, 25, 11963-11974. [CrossRef] [PubMed]

47. Yuan, F.; Li, S.; Fan, Z.; Meng, X.; Fan, L.; Yang, S. Shining carbon dots: Synthesis and biomedical and optoelectronic applications. Nano Today 2016, 11. [CrossRef]

48. Li, X.; Zhang, S.; Kulinich, S.A.; Liu, Y.; Zeng, H. Engineering surface states of carbon dots to achieve controllable luminescence for solid-luminescent composites and sensitive $\mathrm{Be}^{2+}$ detection. Sci. Rep. 2014, 4, 1-8. [CrossRef]

49. Kandasamy, G. Recent advancements in doped/co-doped carbon quantum dots for multi-potential applications. C J. Carbon Res. 2019, 5, 24. [CrossRef]

50. Mandal, B.; Sarkar, S.; Sarkar, P. Exploring the electronic structure of graphene quantum dots. J. Nanoparticle Res. 2012, 14. [CrossRef]

51. Li, Y.; Shu, H.; Niu, X.; Wang, J. Electronic and optical properties of edge-functionalized graphene quantum dots and the underlying mechanism. J. Phys. Chem. C 2015, 119, 24950-24957. [CrossRef]

52. Yamijala, S.S.; Bandyopadhyay, A.; Pati, S.K. Structural stability, electronic, magnetic, and optical properties of rectangular graphene and boron nitride quantum dots: Effects of size, substitution, and electric field. J. Phys. Chem. C 2013, 117, 23295-23304. [CrossRef]

53. Güttinger, J.; Stampfer, C.; Frey, T.; Ihn, T.; Ensslin, K. Graphene quantum dots in perpendicular magnetic fields. Phys. Status Solidi 2009, 246, 2553-2557. [CrossRef]

54. Li, X.; Lau, S.P.; Tang, L.; Ji, R.; Yang, P. Sulphur doping: A facile approach to tune the electronic structure and optical properties of graphene quantum dots. Nanoscale 2014, 6, 5323-5328. [CrossRef] [PubMed]

55. Tao, S.; Zhu, S.; Feng, T.; Xia, C.; Song, Y.; Yang, B. The polymeric characteristics and photoluminescence mechanism in polymer carbon dots: A review. Mater. Today Chem. 2017, 6. [CrossRef]

56. Guo, W.; Luo, Y.; Wei, K.; Gao, X. A cellular level biocompatibility and biosafety evaluation of mesoporous SiO2-based nanocomposite with lanthanum species. J. Mater. Sci. 2011, 47, 1514-1521. [CrossRef]

57. Ge, J.; Lan, M.; Zhou, B.; Liu, W.; Guo, L.; Wang, H.; Jia, Q.; Niu, G.; Huang, X.; Zhou, H.; et al. A graphene quantum dot photodynamic therapy agent with high singlet oxygen generation. Nat. Commun. 2014, 5, 1-8. [CrossRef] [PubMed]

58. Tang, L.; Ji, R.; Li, X.; Bai, G.; Liu, C.P.; Hao, J.; Lin, J.; Jiang, H.; Teng, K.S.; Yang, Z.; et al. Deep ultraviolet to near-infrared emission and photoresponse in layered n-doped graphene quantum dots. ACS Nano 2014, 8, 6312-6320. [CrossRef] [PubMed]

59. Shamsipur, M.; Barati, A.; Karami, S. Long-wavelength, multicolor, and white-light emitting carbon-based dots: Achievements made, challenges remaining, and applications. Carbon N. Y. 2017, 124. [CrossRef]

60. Song, Y.; Zhu, S.; Zhang, S.; Fu, Y.; Wang, L.; Zhao, X.; Yang, B. Investigation from chemical structure to photoluminescent mechanism: A type of carbon dots from the pyrolysis of citric acid and an amine. J. Mater. Chem. C 2015, 3, 5976-5984. [CrossRef]

61. Wang, Y.; Li, Y.; Yan, Y.; Xu, J.; Guan, B.; Wang, Q.; Li, J.; Yu, J. Luminescent carbon dots in a new magnesium aluminophosphate zeolite. Chem. Commun. 2013, 49, 9006-9008. [CrossRef] [PubMed]

62. Xu, Q.; Kuang, T.; Liu, Y.; Cai, L.; Peng, X.; Sreenivasan Sreeprasad, T.; Zhao, P.; Yu, Z.; Li, N. Heteroatom-doped carbon dots: Synthesis, characterization, properties, photoluminescence mechanism and biological applications. J. Mater. Chem. B 2016, 4, 7204-7219. [CrossRef] [PubMed]

63. Li, L.; Dong, T. Photoluminescence tuning in carbon dots: Surface passivation or/and functionalization, heteroatom doping. J. Mater. Chem. C 2018, 6, 7944-7970. [CrossRef]

64. Yan, F.; Sun, Z.; Zhang, H.; Sun, X.; Jiang, Y.; Bai, Z. The fluorescence mechanism of carbon dots, and methods for tuning their emission color: A review. Microchim. Acta 2019, 186, 583. [CrossRef] [PubMed] 
65. Yuan, F.; Wang, Z.; Li, X.; Li, Y.; Tan, Z.; Fan, L.; Yang, S. Bright multicolor bandgap fluorescent carbon quantum dots for electroluminescent light-emitting diodes. Adv. Mater. 2017, 29. [CrossRef] [PubMed]

66. Ding, Y.; Zhang, F.; Xu, J.; Miao, Y.; Yang, Y.; Liu, X.; Xu, B. Synthesis of short-chain passivated carbon quantum dots as the light emitting layer towards electroluminescence. RSC Adv. 2017, 7, 28754-28762. [CrossRef]

67. Miao, X.; Qu, D.; Yang, D.; Nie, B.; Zhao, Y.; Fan, H.; Sun, Z. Synthesis of carbon dots with multiple color emission by controlled graphitization and surface functionalization. Adv. Mater. 2018, 30, 1704740. [CrossRef]

68. Shi, L.; Yang, J.H.; Zeng, H.B.; Chen, Y.M.; Yang, S.C.; Wu, C.; Zeng, H.; Yoshihito, O.; Zhang, Q. Carbon dots with high fluorescence quantum yield: The fluorescence originates from organic fluorophores. Nanoscale 2016, 8, 14374-14378. [CrossRef]

69. Song, Y.; Zhu, S.; Yang, B. Bioimaging based on fluorescent carbon dots. RSC Adv. 2014, 4, 27184-27200. [CrossRef]

70. Ding, H.; Yu, S.B.; Wei, J.S.; Xiong, H.M. Full-color light-emitting carbon dots with a surface-state-controlled luminescence mechanism. ACS Nano 2016, 10, 484-491. [CrossRef]

71. Zheng, X.; Wang, H.; Gong, Q.; Zhang, L.; Cui, G.; Li, Q.; Chen, L.; Wu, F.; Wang, S. Highly luminescent carbon nanoparticles as yellow emission conversion phosphors. Mater. Lett. 2015, 143. [CrossRef]

72. Joseph, J.; Anappara, A.A. White-light-emitting carbon dots prepared by the electrochemical exfoliation of graphite. ChemPhysChem 2017, 18, 292-298. [CrossRef]

73. Wang, F.; Chen, Y.; Liu, C.; Ma, D. White light-emitting devices based on carbon dots' electroluminescence. Chem. Commun. 2011, 47, 3502. [CrossRef]

74. Paulo-Mirasol, S.; Martínez-Ferrero, E.; Palomares, E. Direct white light emission from carbon nanodots (C-dots) in solution processed light emitting diodes. Nanoscale 2019, 11, 11315-11321. [CrossRef] [PubMed]

75. Zhang, X.; Zhang, Y.; Wang, Y.; Kalytchuk, S.; Kershaw, S.V.; Wang, Y.; Wang, P.; Zhang, T.; Zhao, Y.; Zhang, H.; et al. Color-switchable electroluminescence of carbon dot light-emitting diodes. ACS Nano 2013, 7, 11234-11241. [CrossRef] [PubMed]

76. Xu, J.; Miao, Y.; Zheng, J.; Wang, H.; Yang, Y.; Liu, X. Carbon dot-based white and yellow electroluminescent light emitting diodes with a record-breaking brightness. Nanoscale 2018, 10, 11211-11221. [CrossRef] [PubMed]

77. Yuan, F.; Wang, Y.-K.; Sharma, G.; Dong, Y.; Zheng, X.; Li, P.; Johnston, A.; Bappi, G.; Fan, J.Z.; Kung, H.; et al. Bright high-colourpurity deep-blue carbon dot light-emitting diodes via efficient edge amination. Nat. Photonics 2020, 14. [CrossRef]

78. Yuan, F.; Yuan, T.; Sui, L.; Wang, Z.; Xi, Z.; Li, Y.; Li, X.; Fan, L.; Tan, Z.; Chen, A.; et al. Engineering triangular carbon quantum dots with unprecedented narrow bandwidth emission for multicolored LEDs. Nat. Commun. 2018, 9, 1-11. [CrossRef] [PubMed]

79. Singh, A.; Wolff, A.; Yambem, S.D.; Esmaeili, M.; Riches, J.D.; Shahbazi, M.; Feron, K.; Eftekhari, E.; Ostrikov, K.; Li, Q.; et al. Biowaste-derived, self-organized arrays of high-performance $2 \mathrm{~d}$ carbon emitters for organic light-emitting diodes. Adv. Mater. 2020, 32, 1906176. [CrossRef]

80. Jia, H.; Wang, Z.; Yuan, T.; Yuan, F.; Li, X.; Li, Y.; Tan, Z.; Fan, L.; Yang, S. Electroluminescent warm white light-emitting diodes based on passivation enabled bright red bandgap emission carbon quantum dots. Adv. Sci. 2019, 6, 1900397. [CrossRef]

81. Xu, J.; Miao, Y.; Zheng, J.; Yang, Y.; Liu, X. Ultrahigh brightness carbon dot-based blue electroluminescent leds by host-guest energy transfer emission mechanism. Adv. Opt. Mater. 2018, 6, 1800181. [CrossRef]

82. Zhang, X.; Zeng, Q.; Xiong, Y.; Ji, T.; Wang, C.; Shen, X.; Lu, M.; Wang, H.; Wen, S.; Zhang, Y.; et al. Energy level modification with carbon dot interlayers enables efficient perovskite solar cells and quantum dot based light-emitting diodes. Adv. Funct. Mater. 2020, 30, 1910530. [CrossRef]

83. Alam, M.B.; Yadav, K.; Shukla, D.; Srivastava, R.; Lahiri, J.; Parmar, A.S. Carbon quantum dot as electron transporting layer in organic light emitting diode. ChemistrySelect 2019, 4, 7450-7454. [CrossRef]

84. Park, Y.R.; Jeong, H.Y.; Seo, Y.S.; Choi, W.K.; Hong, Y.J. Quantum-dot light-emitting diodes with nitrogen-doped carbon nanodot hole transport and electronic energy transfer layer. Sci. Rep. 2017, 7, 1-13. [CrossRef] [PubMed]

85. Cappelli, A.; Villafiorita-Monteleone, F.; Grisci, G.; Paolino, M.; Razzano, V.; Fabio, G.; Giuliani, G.; Donati, A.; Mendichi, R.; Boccia, A.C.; et al. Highly emissive supramolecular assemblies based on $\pi$-stacked polybenzofulvene hosts and a benzothiadiazole guest. J. Mater. Chem. C 2014, 2, 7897-7905. [CrossRef]

86. Botta, C.; Betti, P.; Pasini, M. Organic nanostructured host-guest materials for luminescent solar concentrators. J. Mater. Chem. A 2013, 1, 510-514. [CrossRef]

87. Giovanella, U.; Pasini, M.; Lorenzon, M.; Galeotti, F.; Lucchi, C.; Meinardi, F.; Luzzati, S.; Dubertret, B.; Brovelli, S. Efficient solution-processed nanoplatelet-based light-emitting diodes with high operational stability in air. Nano Lett. 2018, 18, 3441-3448. [CrossRef]

88. Castelli, A.; Meinardi, F.; Pasini, M.; Galeotti, F.; Pinchetti, V.; Lorenzon, M.; Manna, L.; Moreels, I.; Giovanella, U.; Brovelli, S. High-efficiency all-solution-processed light-emitting diodes based on anisotropic colloidal heterostructures with polar polymer injecting layers. Nano Lett. 2015, 15, 5455-5464. [CrossRef]

89. Pasini, M.; Giovanella, U.; Betti, P.; Bolognesi, A.; Botta, C.; Destri, S.; Porzio, W.; Vercelli, B.; Zotti, G. The role of triphenylamine in the stabilization of highly efficient polyfluorene-based OLEDs: A model oligomers study. ChemPhysChem 2009, 10, 2143-2149. [CrossRef]

90. Paulo-Mirasol, S.; Gené-Marimon, S.; Martínez-Ferrero, E.; Palomares, E. Inverted hybrid light-emitting diodes using carbon dots as selective contacts: The effect of surface ligands. ACS Appl. Electron. Mater. 2020, 2, 1388-1394. [CrossRef]

91. Meloni, M.; Souchet, F.; Sturges, D. Circular-Consumer-Electronics-2704: An Initial Exploration; Ellen MacArthur Foundation: Cowes, UK, 2018. 